OPEN ACCESS

Edited by:

Shimon Meir,

Agricultural Research Organization,

Israel

Reviewed by:

Grama Nanjappa Dhanapal, University of Agricultural Sciences,

Agata Gadaleta

University of Bari, Italy

Amnon Lichter

The Volcani Center, Israel

*Correspondence:

Luis F. Goulao,

Agri4Safe-BioTrop, Instituto de Investigação Científica Tropical I.P., Pólo Mendes Ferrão, Edificio Ferreira Lapa - Tapada da Ajuda, 1349-017

Lisboa, Portugal goulao@iict.pt

Specialty section:

This article was submitted to Crop Science and Horticulture,

a section of the journal

Frontiers in Plant Science

Received: 14 March 2015 Accepted: 08 June 2015

Published: 22 June 2015

Citation:

Domingos S, Scafidi $P$, Cardoso $V$

Leitao AE, Di Lorenzo R, Oliveira CM and Goulao LF (2015) Flower abscission in Vitis vinifera L. triggered by gibberellic acid and shade discloses differences in the underlying metabolic pathways.

Front. Plant Sci. 6:457. doi: 10.3389/fpls.2015.00457

\section{Flower abscission in Vitis vinifera L. triggered by gibberellic acid and shade discloses differences in the underlying metabolic pathways}

\author{
Sara Domingos ${ }^{1,2}$, Pietro Scafidi ${ }^{3}$, Vania Cardoso ${ }^{2}$, Antonio E. Leitao ${ }^{2}$, \\ Rosario Di Lorenzo ${ }^{3}$, Cristina M. Oliveira ${ }^{1}$ and Luis F. Goulao ${ }^{*}$ \\ ' Linking Landscape, Environment, Agriculture and Food, Instituto Superior de Agronomia, Universidade de Lisboa, Lisbon, \\ Portugal, ${ }^{2}$ Agri4Safe-BioTrop, Instituto de Investigação Científica Tropical I.P., Lisbon, Portugal, ${ }^{3}$ Dipartimento di Scienze \\ Agrarie e Forestali, University of Palermo, Palermo, Italy
}

Understanding abscission is both a biological and an agronomic challenge. Flower abscission induced independently by shade and gibberellic acid (GAc) sprays was monitored in grapevine (Vitis vinifera L.) growing under a soilless greenhouse system during two seasonal growing conditions, in an early and late production cycle. Physiological and metabolic changes triggered by each of the two distinct stimuli were determined. Environmental conditions exerted a significant effect on fruit set as showed by the higher natural drop rate recorded in the late production cycle with respect to the early cycle. Shade and GAc treatments increased the percentage of flower drop compared to the control, and at a similar degree, during the late production cycle. The reduction of leaf gas exchanges under shade conditions was not observed in GAc treated vines. The metabolic profile assessed in samples collected during the late cycle differently affected primary and secondary metabolisms and showed that most of the treatment-resulting variations occurred in opposite trends in inflorescences unbalanced in either hormonal or energy deficit abscission-inducing signals. Particularly concerning carbohydrates metabolism, sucrose, glucose, tricarboxylic acid metabolites and intermediates of the raffinose family oligosaccharides pathway were lower in shaded and higher in GAc samples. Altered oxidative stress remediation mechanisms and indolacetic acid (IAA) concentration were identified as abscission signatures common to both stimuli. According to the global analysis performed, we report that grape flower abscission mechanisms triggered by GAc application and C-starvation are not based on the same metabolic pathways.

Keywords: abscission, gibberellic acid, grapevine, inflorescence, metabolomics, shade, thinning

Abbreviations: ABA, abscisic acid; ACC, 1-aminocyclopropane-1-carboxylic acid; CW, cell wall; DAB, days after bloom; E, transpiration rate; GAc, gibberellic acid; $g s$, stomatal conductance; IAA, indolacetic acid; PAs, polyamines; PAL, phenylalanine; Pn, net photosynthetic rate; ROS, reactive oxygen species; SAH, S-adenosylhomocysteine; SAM, $S$-adenosylmethionine; TCA, tricarboxylic acid. 


\section{Introduction}

Abscission is the process by which vegetative and reproductive organs can be detached from plants as an effect of developmental, hormonal, and environmental cues. Abscission control is regarded as an important agricultural concern because it affects production yield and quality. In fruit species, fruit set is often excessive and the natural drop, which enables the plant to self-regulate its load, is not sufficient to satisfy fresh market quality standards (Bonghi et al., 2000). Fruit thinning is a common practice, particularly in table grape production, in which the reduction of berry number per bunch is mandatory to guarantee improved bunch appearance and quality and decreased diseases incidence (Dokoozlian and Peacock, 2001). Excluding labor-demanding manual thinning, the most common thinning method for table grapes uses chemical treatments with GAc sprays at bloom to induce flower abscission. The effectiveness of this practice is known to vary due to both internal (such as cultivar, phenologic stage, physiological condition, and age) and external (such as nutrient availability, irrigation, temperature, irradiation, and humidity) conditions (Weaver et al., 1962; Hopping, 1976; Looney and Wood, 1977; Dokoozlian, 1998; Dokoozlian and Peacock, 2001; Reynolds and Savigny, 2004; Reynolds et al., 2006; Hed et al., 2011). Gibberellins participate in biological processes such as cell elongation, dormancy breaking, parthenocarpy induction, and seed germination (Yamaguchi, 2008; Davière and Achard, 2013). However, despite the widespread use of GAc spraying, the mechanisms by which GAc works as thinning agent are not fully understood. According to the photosynthates competition hypothesis (Dokoozlian, 1998), GAc stimulates general organ growing, inducing competition for nutrients between flowers and shoots and/or among flowers within the inflorescence, which leads to reductions in the amount of nutrients available for berry set and growth. Alternatively, GAc can be responsible for unbalancing hormone relative concentrations, in agreement with the hormone balance hypothesis (Dokoozlian, 1998). Auxins are known to regulate gibberellin endogenous levels (Yamaguchi, 2008). A flow of inhibitory auxin in an organ destined to abscise prevents cell separation until its endogenous levels drop, derepressing ethylene, which then activates the transcription of CW disassembly related genes (Else et al., 2004; Dal Cin et al., 2005). The effect of shade imposition to promote berry set reduction has been first investigated by Roubelakis and Kliewer (1976) and Ferree et al. (2001). The use of this practice as an alternative thinning method was successful also in other species, such as apple (Schneider, 1975; Byers et al., 1985, 1990, 1991; Corelli Grappadelli et al., 1990; Widmer et al., 2008; Zibordi et al., 2009; Basak, 2011) and involves intercepted light reduction during a short period of time after bloom. The pronounced reduction of net photosynthetic rate under shading promotes the competition for photoassimilates between vegetative and reproductive organs, leading to shedding of the later, which have less sink strength at this early stage of development (Vasconcelos et al., 2009). Hence, abscission stands as challenging biological question since it can be induced by agents that apparently act by promoting opposite changes to the plant physiology. However, although the hormone and the assimilate theories may look contrasting, changes in assimilate availability may be the trigger required for changing hormone balances, leading to abscission. Moreover, sugars are more than an energy source as may also act as messengers operating in gene expression regulation or as signaling molecules (Lebon et al., 2008).

The mechanisms underlying organ abscission, were recently reviewed by Estornell et al. (2013), and involve signal peptides and specific receptors, mostly regulated by hormones, in which ethylene, ABA, and jasmonic acid act as accelerating signals. Conversely, auxin, gibberellins, PAs, and brassinosteroids act in abscission inhibiting signaling. The developmental phenomenon of physiological drop represents the natural reduction of fruit set and enables the plant to shed the weaker sinks, regulating the fruit load according to its capacity to produce the metabolic energy required to complete the development of reproductive and vegetative structures (Bonghi et al., 2000). Natural drop occurs after an increased ABA and ethylene production that induces a negative feedback in fruit development, as demonstrated in apple (Botton et al., 2011). In wine grapes, natural drop was showed to be related to lower sugar and PAs availability for developing flowers (Aziz, 2003; Lebon et al., 2004). Declines in the sugar supply at meiosis results in excessive flower abortion in this species (Lebon et al., 2008) which together with the expression of sucrose- or hexose-transporter genes (Davies et al., 1999), suggests a role for sugars in flower stress avoidance. Free-PA synthesis is also closely related to the onset of ovarian development and retards abscission (Aziz, 2003). Since PAs and ethylene share SAM as a common intermediate, SAM may be alternatively channeled toward the PA pathway, functioning as an alternative control. Free PAs fluctuate in parallel with sugars in the grape inflorescence, suggesting also a contribution in the modulation of their concentrations (Aziz, 2003).

Changes on the biochemical and transcriptome profiles during flower and fruit abscission triggered by growth regulators (Whitelaw et al., 2002; Dal Cin et al., 2005, 2009; Li and Yuan, 2008; Meir et al., 2010; Botton et al., 2011; Giulia et al., 2013; Peng et al., 2013; Wang et al., 2013) or by low light conditions (Aziz, 2003; Zhou et al., 2008; Li et al., 2013) have been studied in several species such as tomato (Solanum lycopersicon), apple (Malus domestica), lychee (Litchi chinensis), or wine grapes aiming at understanding the effect caused by chemical/environmental perturbations. The above-cited studies revealed a coordinated response of hormones, ROS, sugar metabolism, and signaling pathways to determine the downstream activation of abscission which includes increased activity of $\mathrm{CW}$-modifying enzymes. Nonetheless, to our knowledge, only one publication to date (Zhu et al., 2011) reports a direct comparison of the mechanisms underlying abscission triggered by two distinct cues. The authors compared napththaleneacetic acid (NAA) and shading treatments in inducing abscission in apple, through transcriptome analysis, and observed shared pathways involving reduction of photosynthesis, carbon transport and signaling, and hormone crosstalk. The aim of the present study was to provide a first global approach for understanding the 
changes occurring in vine inflorescences and canopy that explain flower abscission in Vitis vinifera L. (Black Magic table grape cultivar), triggered by two contrasting abscission-inducing treatments (shade and GAc spraying) under conditions that leading to similar berry shed rates. The goal was to search for specificities and common links in metabolic pathways that control abscission.

\section{Materials and Methods}

\section{Experimental Conditions and Design}

The trails were carried out in a greenhouse in the south of Sicily, in a soilless table grape commercial production system (Di Lorenzo et al., 2014) of 'Black Magic' vines (V. vinifera L.) own-rooted in 2010 (Figure 1A). Black Magic is a very early seeded table grape cultivar, with high fertility and yield, released by the National Research Institute of Grape and Wine in Chisinau, Moldova. The assays were performed during the late production cycle of 2011 and the early production cycle of 2012. Plants were spaced $1.60 \mathrm{~m}$ between lines $\times 0.40 \mathrm{~m}$ between plants, trained as unilateral cordon pruned with six buds and managed following integrated fertilization, irrigation, and pest-management practices (Di Lorenzo et al., 2009). The number of fertirrigations ranged between 5 and 20, judged by monitoring microclimate conditions. Nutritive solutions had the composition of $3,1.25,0.5,0.65,0.75,0.5,1.25,7,0.75,2$, and $0.5 \mathrm{mM}$ of $\mathrm{Ca}, \mathrm{Mg}, \mathrm{Na}, \mathrm{K}, \mathrm{NH}_{4}, \mathrm{Si}, \mathrm{P}, \mathrm{NO}_{3}, \mathrm{HCO}_{3} / \mathrm{CO}_{3}, \mathrm{SO}_{4}$, and $\mathrm{Cl}$, respectively, the $\mathrm{pH}$ was 5.0 and the electrical conductivity was maintained between 1.5 and $2 \mathrm{~ms} \mathrm{~cm}^{-1}$. Treatments were: (i) reduction of intercepted light and (ii) chemical thinning with GAc, both established at bloom (50\% cap fall, stage 65 of the BBCH scale Lorenz et al., 1994). Shade treatments entailed covering the vines with green polypropylene $90 \%$ nets (Serroplast, Italy) for a period of 12 days. Chemical treatment consisted in spraying GAc (Gibberellin 1.8\% GA, Gobbi, Italy) at $15 \mathrm{ppm}$ concentration. A group that remained untreated was included as control. Experiments were designed in three randomized blocks by treatment with 14 vines each, using single vines as replicates. Climate conditions were monitored above the canopy of shaded and control vines (WatchDog MicroStation, Spectrum Tech., USA; Supplementary Figure S1).

\section{Late Production Cycle}

Plants were kept stored cold until June 2011 and the experiments started at 3rd July. The 50\% cap fall stage (bloom) occurred after 34 days and harvest was carried out 67 DAB. This production cycle lasted a total of 101 days. The day (7 a.m. to 7 p.m.)/night (7 p.m. to 7 a.m.) mean temperatures registered were $32 / 23^{\circ} \mathrm{C}$, relative humidity was $41 / 64 \%$ and PAR was $5 / 504 \mu \mathrm{mol} \mathrm{m} \mathrm{m}^{-2} \mathrm{~s}^{-1}$.

\section{Early Production Cycle}

The experiments were conducted in 2012 using the same plants as in the previous year. The early production cycle started at 9 February, 50\% cap fall stage occurred after 53 days and grapes were harvested $77 \mathrm{DAB}$. This cycle lasted a total of 130 days. The recorded day/night mean temperatures were $26 / 14^{\circ} \mathrm{C}$, relative humidity was $45 / 79 \%$ and PAR was $17 / 566 \mu \mathrm{mol} \mathrm{m}^{-2} \mathrm{~s}^{-1}$.

\section{Vine Physiology Monitoring}

Flower and berry drop were monitored by positioning nonwoven cloth bags around bunches at $50 \%$ cap fall after the imposition of each treatment, to collect the shed flowers (Figures 1B,C). Flowers were collected and counted, 2, 4, and 12 $\mathrm{DAB}$ in 10 bunches per treatment. Bunches were selected taking uniformity of bloom in account. At harvest, the same bunches were collected and the final number of berries was recorded to calculate the cumulative and daily rate berry drop percentages. Net Pn, E and gs were measured in the morning period (9:0011:00 a.m.) using a portable infrared gas analyzer (CIRAS, PPsystems, UK) on 12 mature leaves from the central part of the shoot, twice during the shade period (at 3 and $10 \mathrm{DAB}$ ). Shoot length, estimated leaf chlorophyll content (SPAD-502 m, Minolta, Japan) and total (sum of primary and secondary) leaf area (WinDIAS leaf area measurement system, Delta-T Devices, $\mathrm{UK}$ ) were determined $12 \mathrm{DAB}$, before removal of the shade nets, in nine shoots per treatment.

\section{Metabolic Analysis \\ Quantification of Target Metabolites}

Sugar (glucose, sucrose, fructose, and stachyose), free PA (putrescine, spermine, spermidine, and cadaverine) and hormone (IAA and ABA) contents extracted from inflorescence samples collected in the late cycle, 1,3 , and $4 \mathrm{DAB}$ were quantified
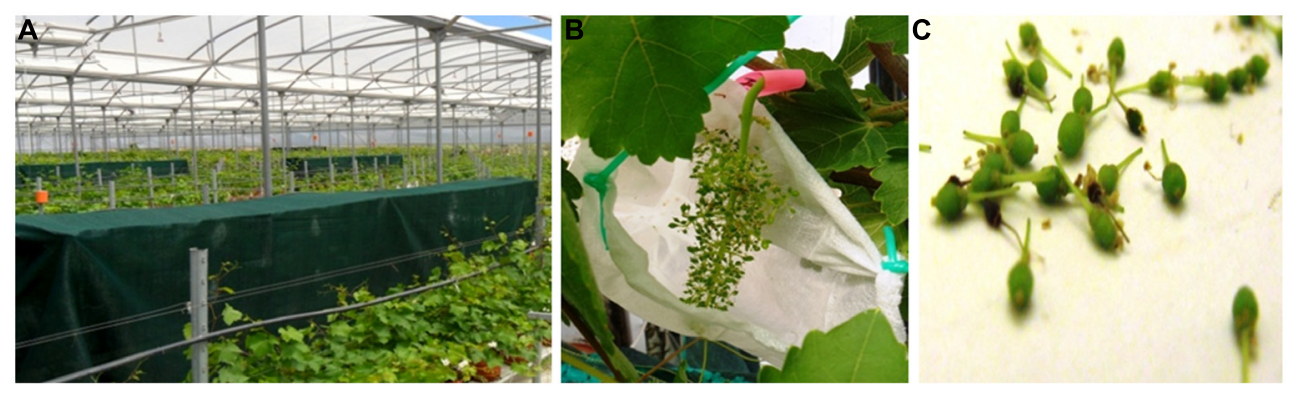

FIGURE 1 | Aspect of the experimental table grape vines (Black Magic cv) growing in greenhouse conditions (A), monitoring of flowers drop (B) and flowers detached from the base of flower pedicel (C) after abscission-inducing treatments application. 
by high performance liquid chromatography (HPLC), aiming at determining the metabolic changes explaining flower abscission. The biochemical analyses were conducted using liquid nitrogen frozen powdered samples of whole inflorescences deprived from the rachis. Samples for soluble sugars quantification $(100 \mathrm{mg})$ were extracted according to Damesin and Lelarge (2003), and samples were injected into a HPLC (Beckman Coulter, USA) and separated on a Sugar-Pak I column I $(300 \times 6.5 \mathrm{~mm}$, Waters $)$ at $90^{\circ} \mathrm{C}$ under a $122 \mu \mathrm{M}$ EDTA-Ca solution and a flow rate of $0.5 \mathrm{ml} \mathrm{min}{ }^{-1}$. Peaks were detected by RI (Refractive Index Detector 2414, Waters). Free PAs were quantified according to Smith and Davies (1987) with modifications. Samples (100 mg) were mixed with $300 \mu \mathrm{L}$ of a $5 \%$ perchloric acid solution, kept for $50 \mathrm{~min}$ in ice and centrifuged for $20 \mathrm{~min}$ at $20000 \mathrm{~g}$ at $4^{\circ} \mathrm{C}$. Saturated $\mathrm{Na}_{2} \mathrm{CO}_{3}(200 \mu \mathrm{l})$ and dansyl chloride $(400 \mu \mathrm{L}$, $5 \mathrm{mg} \mathrm{ml}^{-1}$ in acetone) were added to $100 \mu \mathrm{l}$ of the supernatant, and mixtures were incubated in the dark at $60^{\circ} \mathrm{C}$ for $1 \mathrm{~h}$. Proline $(10 \mathrm{mg})$ was then added and further incubated for $30 \mathrm{~min}$. PAs were extracted with $500 \mu \mathrm{l}$ of toluene, the organic phase was dried under nitrogen and the residue was dissolved in $300 \mu \mathrm{l}$ acetonitrile. The resulting samples were injected into the HPLC (Ultimate 3000, Dionex, Sunnyville, CA, USA), eluted through a C18 column (particle size $5 \mu \mathrm{m}$, $4.6 \times 150 \mathrm{~mm}$, Thermo Scientific) at a flow rate of $1 \mathrm{ml}$ $\min ^{-1}$ with a mobile phase consisting of $10 \%$ acetonitrile solution, $\mathrm{pH} 3.5$ (solvent A) and acetonitrile (solvent B) using a 60 to $90 \%$ of solvent A gradient, during $23 \mathrm{~min}$. Peaks were detected with a diode array detector (DAD) at $346 \mathrm{~nm}$. IAA and ABA were extracted according to Kelen et al. (2004) with modifications. Samples $(200 \mathrm{mg})$ were extracted with $600 \mu \mathrm{L}$ of $70 \%$ methanol and incubated at $4^{\circ} \mathrm{C}$ overnight. The extraction was repeated twice and the methanol evaporated under vacuum. 0.1 $\mathrm{M}$ phosphate buffer $(800 \mu \mathrm{l})$ was added to the aqueous phase and partitioned with $300 \mu \mathrm{l}$ of ethyl acetate three times. After ethyl acetate removal, the $\mathrm{pH}$ was adjusted to 2.5 with $1 \mathrm{~N} \mathrm{HCl}$. The solution was further partitioned three times with $450 \mu \mathrm{l}$ of diethyl ether, passed through anhydrous sodium sulfate, evaporated at $50^{\circ} \mathrm{C}$ under vacuum and the residue was dissolved in $100 \mu \mathrm{l}$ of methanol. Aliquots were injected into the HPLC (Ultimate 3000, Dionex, Sunnyville, CA, USA), eluted through a C18 column (particle size $5 \mu \mathrm{m}$, $4.6 \times 150 \mathrm{~mm}$, Thermo Scientific) under a $30 \mathrm{mM}$ phosphoric acid solution with $26 \%$ acetonitrile at $4 \mathrm{pH}$ during $30 \mathrm{~min}$ at $0.8 \mathrm{ml} \mathrm{min}^{-1}$ and the peaks were detected with a DAD at 208 and $265 \mathrm{~nm}$. In all cases, extractions were done in duplicate readings, each from three biological replicates per treatment. Standards for peak identification were purchased from SigmaAldrich $^{\circledR}$.

\section{Global Metabolomic Profile}

Sample points for metabolomic analysis were chosen based on the significant changes observed after target chromatography quantifications. Therefore, samples from three biological replicates $(200 \mathrm{mg})$ of GAc-, shaded-treated and control inflorescences collected at $4 \mathrm{DAB}$ in the late production cycle, were lyophilized, methanol extracted, and analyzed using the integrated platform developed by Metabolon ${ }^{\circledR}$ (Durham, USA) consisting of a combination of three independent approaches: (1) ultrahigh performance liquid chromatography/tandem mass spectrometry (UHLC/MS/MS2) optimized for basic species, (2) UHLC/MS/MS2 optimized for acidic species, and (3) gas chromatography/mass spectrometry (GC/MS). Methods were followed as previously described (Evans et al., 2009; Ohta et al., 2009).

\section{Evaluation of Productivity and Berry Quality Attributes}

The final number of shot berries (parthenocarpic small berries that remain green at harvest) and regular-sized berries, bunch weight, rachis length and weight, bunch compactness (ratio between total number of berries and length of the rachis) and yield per plant (product of the bunch weight by number of bunches per plant) were recorded and calculated at harvest in the same 10 bunches per treatment used for flower drop monitoring. Ten berries per bunch were randomly selected to measure berries weight and diameter. The remaining berries were distributed in three samples per treatment to measure total soluble solids (TSS; in ${ }^{\circ}$ Brix using a PR-32 refractometer, Atago, Japan) and titratable acidity (TA; by potentiometric titration with $0.1 \mathrm{~N} \mathrm{NaOH}$ up to $\mathrm{pH}$ 8.1).

\section{Data Imputation and Statistical Analysis}

To access the significance of the differences observed between treatments and production cycles, variance analysis (oneand two-way ANOVA) and post hoc (Tukey's HSD with $\alpha=0.05$ ) tests were conducted using Statistix 9 (Analytical Software, Tallahassee, FL, USA). To improve adjustment to the normal distribution, percentage values were $\arcsin \operatorname{sqrt}(\mathrm{x})$ transformed and values concerning number of berries were square-root transformed. For global metabolomic analyses, raw area counts for each biochemical were rescaled by dividing each sample's value by the median value for the specific metabolite. Following $\log _{2}$ transformations, statistical analysis of the data was performed using Array Studio (Omicsoft). In order to visualize the results, a heat map was generated to show fold change (FC) defined as the $\log _{2}$ of the means ratio of each treatment and control for each compound (Supplementary Figure S2). Welch's two-sample $t$-tests were used to determine whether each metabolite had significantly increased or decreased in abundance. False discovery rates (FDRs) were calculated as $q$-values according to Storey and Tibshirani (2003) to account for the large number of tests. Metabolites that significantly changed in response to at least one of the imposed treatments were used to conduct correlation matrix-based principal component analysis (PCA) and hierarchical clustering. Dendrograms associated with the heatmap and approximately unbiased and bootstrap probability $P$-values were computed using pvclust version 1.3.2 (Suzuki and Shimodaira, 2006) with the UPGMA method and 1000 bootstrap replications. Box plots were generated for those compounds that showed a significant increase or decrease using both the Welch two-sample $t$-test, FDR (i.e., $P<0.05$ and $q<0.10)$ significance values and $|\mathrm{FC}| \geq 1$. Mapping of named metabolites was performed onto general biochemical pathways, provided in the Kyoto Encyclopedia of 
Genes and Genomes (KEGG ${ }^{1}$ ) and Plant Metabolic Network $\left(\mathrm{PMN}^{2}\right)$.

\section{Results}

\section{Effect of GAc and Shade on Flower Abscission}

The purpose of the treatments was to induce flower abscission, triggered by two distinct stimuli, with distinct physiological basis. In the late production cycle, both shade and GAc treatments resulted in higher cumulative percentages of berry drop $(95.9 \%$ in the shade and $94.3 \%$ in the GAc treatment) comparing to the natural drop values observed in control bunches $(81.0 \%$; Table 1). Similarly, the average daily number of berries drop was highest in the shade treatment $(115 \pm 20$ berries dropped per bunch per day), followed by GAc ( $62 \pm 14$ berries dropped per bunch per day) and lower in the control ( $28 \pm 4$ berries dropped per bunch per day) between 2 and $4 \mathrm{DAB}$ (Figure 2A). In the early production cycle, shade imposition was the treatment that promoted the highest percentage of berries drop (49.4\%; Table 1). This effect was reflected by an average higher daily number of dropped berries during 2-4 and 4-12 DAB intervals (13 \pm 5 and $104 \pm 26$ berries dropped per bunch per day, respectively),

${ }^{1}$ www.genome.jp/kegg/

${ }^{2}$ www.plantcyc.org/ when compared to control $(1 \pm 0.5$ and $29 \pm 10$ berries dropped per bunch per day, respectively) and GAc treatments $(0.3 \pm 0.2$ and $10 \pm 3$ berries dropped per bunch per day, respectively; Figure 2B). Based on these results, the metabolic composition of samples collected in the late cycle, treated with hormonal and light stress abscission-inducing signals, was analyzed.

\section{Impacts on Vine Physiology}

Natural flower drop was significantly affected by environmental factors, exerting a significant effect on fruit set (Table 1). A higher drop rate occurred in the late production cycle (81\%) when compared to the early cycle (16.9\%). Comparing shaded with unshaded conditions, a $90 \%$ PAR reduction was observed, while no significant differences in temperature and relative humidity were perceived (Supplementary Figure S1). On clear sunny day conditions, the 90\%-interception shade cloth provided approximately a maximum PAR of 157 and $170 \mu \mathrm{mol} \mathrm{m} \mathrm{s}^{-1}$ in late and early cycles, respectively, which demonstrates the strong net Pn reduction achieved under shaded conditions, in the magnitudes of 90 and $99 \%$, in the late and early cycle, respectively. Transpiration rate (E; not shown) and $g$ s decreased under shade, only during the early production cycle, by 23 and 54\%, respectively, when compared to controls (Table 1). No differences in shoot length and total leaf area were observed between treatments. Nevertheless, in

TABLE 1 | Effect of shade and GAc treatments on the average percentage of flower drop, total leaf area, and estimated leaf chlorophyll content at 12 $\mathrm{DAB}$, on net photosynthetic rate (Pn) and gs during the shade period in 'Black Magic' vines in late and early cycles.

\begin{tabular}{|c|c|c|c|c|c|c|c|}
\hline $\begin{array}{l}\text { Production } \\
\text { cycle }\end{array}$ & Treatment & $\begin{array}{l}\text { Cumulative } \\
\text { flower drop (\%) }\end{array}$ & $\begin{array}{l}\text { Leaf area } \\
\left(\mathrm{m}^{2} \text { vine }^{-1}\right)\end{array}$ & $\begin{array}{l}\text { Shoot } \\
\text { length }(\mathrm{cm})\end{array}$ & $\begin{array}{l}\text { Leaf chlorophyll } \\
\text { content (spad units) }\end{array}$ & $\begin{array}{l}\mathrm{Pn} \\
\left(\mu \mathrm{mol} \mathrm{m} \mathrm{m}^{-2} \mathrm{~s}^{-1}\right)\end{array}$ & $\begin{array}{l}g s \\
\left(\mathrm{~mol} \mathrm{~m} \mathrm{~m}^{-2} \mathrm{~s}^{-1}\right)\end{array}$ \\
\hline \multirow[t]{3}{*}{ Late } & Control & 81.0 b & 0.52 & 79.4 & 30.5 & $2.72 \mathrm{a}$ & 227.57 \\
\hline & GAc & $94.3 \mathrm{a}$ & 0.62 & 96.3 & 30.3 & $2.12 \mathrm{a}$ & 251.81 \\
\hline & Shade & $95.9 \mathrm{a}$ & 0.58 & 86.8 & 31.7 & $0.26 \mathrm{~b}$ & 153.4 \\
\hline \multirow[t]{3}{*}{ Early } & Control & $16.9 \mathrm{~b}$ & 1.86 & 174.6 & $28.7 \mathrm{ab}$ & $3.23 \mathrm{a}$ & 576.96 a \\
\hline & GAc & $5.4 \mathrm{~b}$ & 1.83 & 183.4 & $28.1 \mathrm{~b}$ & $3.18 \mathrm{a}$ & $613.69 \mathrm{a}$ \\
\hline & Shade & $49.4 \mathrm{a}$ & 1.92 & 158.7 & $31.2 \mathrm{a}$ & $0.04 b$ & $268.89 \mathrm{~b}$ \\
\hline
\end{tabular}

Within each column, different letters indicate significant differences $(P<0.05)$ among treatments, independently in each production cycle, according to Tukey's HSD test.
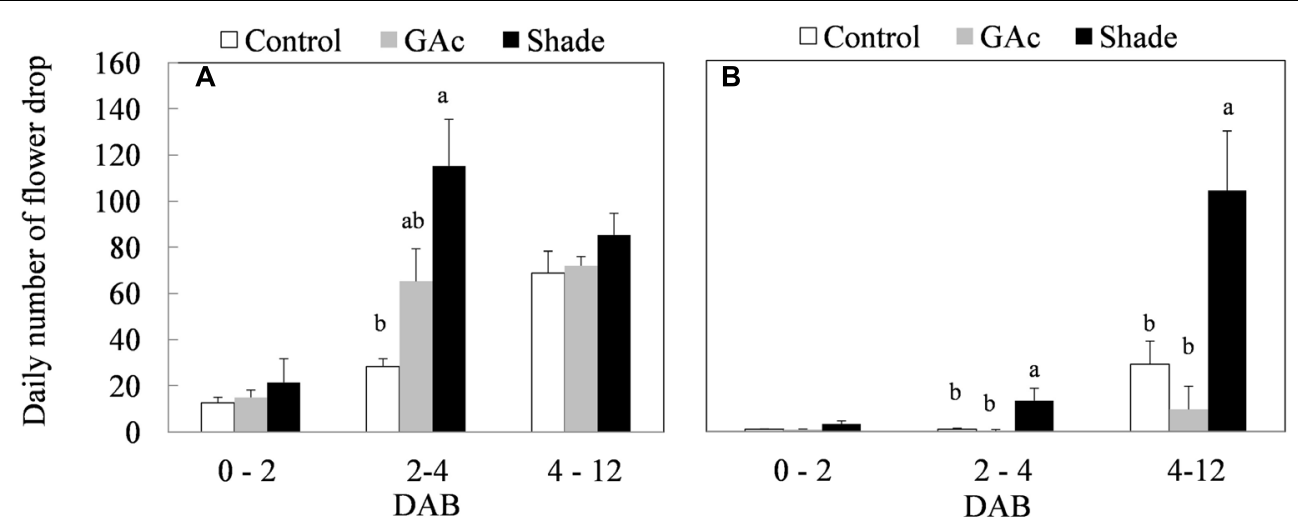

FIGURE 2 | Average daily number of flower drop in summer (A) and spring (B) production cycles as effect of GAc and shade treatments on 'Black Magic' vines (mean \pm SE). Within each sampling date, different letters indicate statistically significant differences $(P<0.05)$. 
TABLE 2 | Effect of shade and GAc treatments on bunch and berries characteristics at harvest in Black Magic table grape cultivar in the late and early cycles.

\begin{tabular}{|c|c|c|c|c|c|c|c|}
\hline $\begin{array}{l}\text { Production } \\
\text { cycle }\end{array}$ & Treatment & $\begin{array}{l}\text { Yield } \\
\left.\text { (kg plant }^{-1}\right)\end{array}$ & Bunch weight (g) & No berries & No shot berries & Rachis length (cm) & Rachis weight (g) \\
\hline \multirow[t]{3}{*}{ Late } & Control & $1.9 \mathrm{a}$ & 315.9 a & $96.8 \mathrm{a}$ & 22.3 & $15.0 \mathrm{ab}$ & $7.7 \mathrm{~b}$ \\
\hline & GAc & $1.1 \mathrm{~b}$ & 193.2 b & $62.1 \mathrm{~b}$ & 29.1 & $17.4 \mathrm{a}$ & $10.4 \mathrm{a}$ \\
\hline & Shade & $0.9 \mathrm{~b}$ & $148.3 \mathrm{~b}$ & $46.2 \mathrm{~b}$ & 14.3 & $12.0 \mathrm{~b}$ & $4.2 \mathrm{c}$ \\
\hline \multirow[t]{4}{*}{ Early } & Control & $8.9 \mathrm{a}$ & 879.8 a & $173.0 \mathrm{a}$ & 188.3 b & $24.1 \mathrm{a}$ & $12.9 \mathrm{a}$ \\
\hline & GAc & $5.6 \mathrm{~b}$ & $555.0 \mathrm{~b}$ & $105.5 \mathrm{~b}$ & $407.1 \mathrm{a}$ & $23.2 \mathrm{a}$ & $10.5 \mathrm{ab}$ \\
\hline & Shade & $5.7 \mathrm{~b}$ & $562.3 b$ & $93.4 \mathrm{~b}$ & $117.6 \mathrm{~b}$ & $20.2 b$ & $7.8 \mathrm{~b}$ \\
\hline & & $\begin{array}{l}\text { Bunch } \\
\text { compactness }\end{array}$ & $\begin{array}{l}\text { Berry diameter } \\
(\mathbf{c m})\end{array}$ & Berry weight (g) & TSS ( ${ }^{\circ}$ Brix) & $\mathrm{TA}\left(\mathrm{g} \mathrm{L}^{-1}\right)$ & \\
\hline \multirow[t]{3}{*}{ Late } & Control & $8.0 \mathrm{a}$ & $14.1 \mathrm{a}$ & $3.83 \mathrm{a}$ & $12.5 b$ & 5.7 & \\
\hline & GAc & $6.1 \mathrm{ab}$ & $13.2 \mathrm{c}$ & $3.47 \mathrm{~b}$ & $14.1 \mathrm{ab}$ & 5.1 & \\
\hline & Shade & $5.1 \mathrm{~b}$ & $13.7 \mathrm{~b}$ & $3.36 \mathrm{~b}$ & $15.5 \mathrm{a}$ & 5.4 & \\
\hline \multirow[t]{3}{*}{ Early } & Control & $15.5 b$ & $17.2 \mathrm{ab}$ & $5.15 \mathrm{c}$ & 13.9 & 3.8 & \\
\hline & GAc & $22.1 \mathrm{a}$ & 16.6 b & 5.18 b & 14.3 & 4.7 & \\
\hline & Shade & 10.5 c & $17.8 \mathrm{a}$ & $5.78 \mathrm{a}$ & 15.8 & 3.8 & \\
\hline
\end{tabular}

Values represent the average of the appropriate number of replicates. Within each column, different letters indicate significant differences $(P<0.05)$ among treatments individually in each production cycle according to Tukey's HSD test.

the early cycle, a higher estimated leaf chlorophyll content was perceived in shaded plants (31.2 spad units) when compared with plants treated with GAc (28.1 spad units; Table 1). Production cycles and the interaction production cycles $\times$ treatment were statistically significantly different regarding cumulative flower drop and $g s(P<0.01)$. Production cycle also affected leaf area, shoot length and leaf chlorophyll content $(P<0.01$; Table 1), impacting final bunch morphology and berry quality (Table 2).

\section{Impacts on Metabolite Content}

Regarding the metabolites analyzed in inflorescences sampled from untreated vines 1,3 , and $4 \mathrm{DAB}$ during the late cycle, the results showed reduced sucrose levels between 1 and 4 DAB (Figure 3A) and increased ABA concentrations, peaking at $3 \mathrm{DAB}$ (Figure $3 \mathrm{E}$ ). Conversely, compared to the control, in shade-treated inflorescences, sucrose concentration decreased at 3 and $4 \mathrm{DAB}$ and fructose and glucose at 4 DAB. In GAc-treated inflorescences, sucrose concentration was highest at $4 \mathrm{DAB}$ (Figure 3B). A significant increase of putrescine content was also observed in the same samples, $4 \mathrm{DAB}$. In samples submitted to the shade treatment, this $\mathrm{PA}$ decreased 3 and $4 \mathrm{DAB}$ (Figure 3D). Cadaverine was not detected. Concerning hormones, IAA concentration was significantly increased in result of both treatments $4 \mathrm{DAB}$ and no differences in $\mathrm{ABA}$ levels were observed between treated inflorescences and controls (Figure 3F). From the 215 metabolites investigated by the global metabolic analyses conducted in samples collected $4 \mathrm{DAB}$, a total of 211 were detected (Supplementary Figure S2) and 48 showed to be differentially changed in abundance $(P<0.05)$ in inflorescences induced for abscission. A total of 34 and 23 metabolites showed differential abundance in shade and GAc treatments, respectively, of which 9 metabolites were common in the different treatments (Table 3). Hierarchical clustering (Figure 4A) showed the association between samples according to the metabolite profile. Samples resulting from each treatment were significantly clustered together. Oleonate, the only metabolite that highly decreased with GAc treatments (FC $=-2$ ) was separated from the other metabolites. Raffinose, sucrose and benzoyl-O-glucose, showed a distinct pattern according to the imposed treatment, and were grouped in a different cluster. PCA (Figure 4B) showed that all samples could be separated according to the treatment to each they were submitted to. The first component allows distinguishing inflorescences developing under shade from all the other samples. GAc samples were separated from controls by the second component. Differentially quantified metabolites were mapped onto general biochemical pathways, and categorized into functional classes as showed in Figure 5. Among the 34 metabolites significantly altered in abundance in shaded inflorescences, those assigned to carbohydrates composed the most prevalent class (38\%), followed by products of secondary metabolism (26\%), amino acid (15\%), nucleotide (9\%), peptide (7\%), cofactors (3\%), and lipids (3\%). Among the 23 metabolites that significantly changed in response to GAc, products from carbohydrate metabolism was also the most prevalent class (52\%), followed by amino acid (18\%), secondary metabolism (13\%), nucleotide (9\%), cofactor (4\%), and hormone (4\%). A list of all metabolites significantly affected by GAc and shade treatments $(P<0.05)$, assigned functional categories, KEGG compound number and respective fold-change is provided in Table 3. Shade and GAc treatments were responsible for a decreased concentration of 24 and four metabolites, respectively, sharing two metabolites derived from the carbohydrate pathway, namely myo-inositol tetrakisphosphate and erythrulose. On the opposite trend, the imposed treatments induced increased concentration of 10 and 19 metabolites, in shade and GAc, 


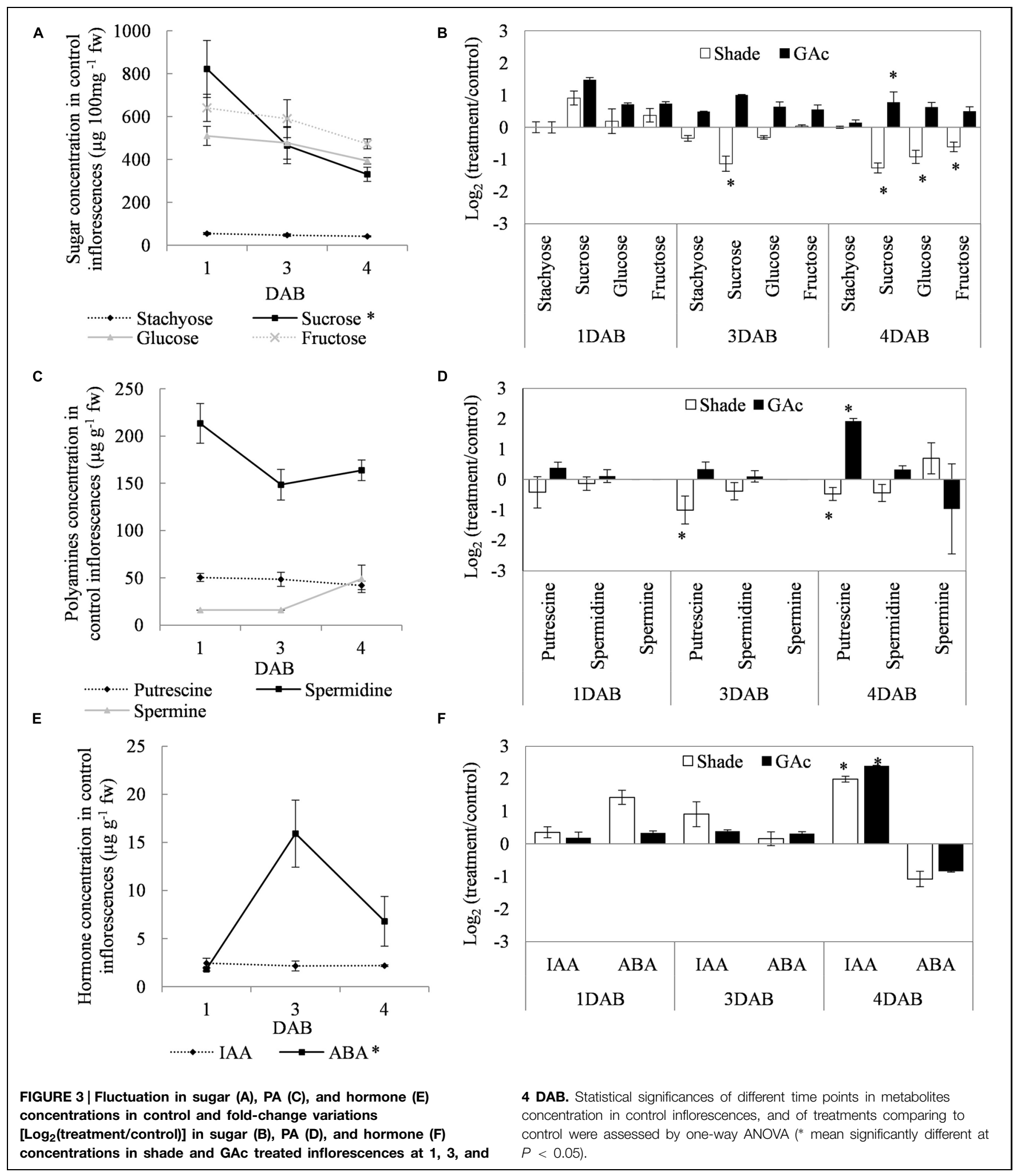

respectively. N6-carbamoylthreonyladenosine, a metabolite from the nucleotide class, was common to both sample sets. Six metabolites concurrently increased in response to GAc and decreased under shade. Four were derived from carbohydrates metabolism, namely sucrose, glucose, raffinose, and malate and the other two were derived from secondary metabolism, and included benzyl alcohol and benzyl-Oglucose. Regarding amino acid pathway, decreased quinate, 
TABLE 3 | List of metabolites significantly affected by GAc and shade treatments $(P<0.05)$, functional categories, KEGG compound number and respective fold-change.

\begin{tabular}{|c|c|c|c|c|}
\hline Super pathway & Compound & KEGG & $\log _{2}\left(\mathrm{GA}_{\mathrm{c}} /\right.$ control) & $\log _{2}$ (shade/control) \\
\hline \multirow[t]{9}{*}{ Amino acid } & 2-Aminobutyrate & C02261 & -1.0 & \\
\hline & Phenethylamine & C02455 & 1.6 & \\
\hline & Quinate & C00296 & & -1.1 \\
\hline & Shikimate & C00493 & & -1.2 \\
\hline & Putrescine & C00134 & & -1.3 \\
\hline & Alanine & C00041 & 0.5 & \\
\hline & Aspartate & C00049 & 0.6 & \\
\hline & Methionine & $\mathrm{C} 00073$ & & 0.7 \\
\hline & S-adenosylhomocysteine (SAH) & $\mathrm{C} 00021$ & & 0.6 \\
\hline \multirow[t]{19}{*}{ Carbohydrate } & 2-Ketogulonate & C02261 & & -1.8 \\
\hline & Ribonate & & 1.3 & \\
\hline & Raffinose & C00492 & 1.4 & -1.6 \\
\hline & Glucose & C00031 & 0.3 & -0.9 \\
\hline & Glucose-6-phosphate (G6P) & C00668 & & -0.5 \\
\hline & Fumarate & C00122 & 0.8 & \\
\hline & Malate & C00149 & 0.7 & -0.8 \\
\hline & Arabonate & C00878 & & 0.8 \\
\hline & Ribitol & C00474 & 0.8 & \\
\hline & Xylose & C00181 & 0.5 & \\
\hline & Ribose & C00121 & 0.5 & \\
\hline & Sucrose & C00089 & 1.3 & -1.7 \\
\hline & Erythrulose & C02045 & -0.8 & -1.6 \\
\hline & Fructose & C00095 & & -0.8 \\
\hline & Mannose-6-phosphate & C00275 & & -0.5 \\
\hline & Citramalate & C00815 & & -0.8 \\
\hline & 1,3-Dihydroxyacetone & C00184 & & -1.5 \\
\hline & Myo-inositol & $\mathrm{C} 00137$ & 0.5 & \\
\hline & $\begin{array}{l}\text { Myo-inositol } 4 \text { kisphosphate } \\
(1,3,4,6 / 3,4,5,6 / 1,3,4,5)\end{array}$ & C01272 & -0.7 & -1.1 \\
\hline Lipids & Glycerol & $\mathrm{C} 00116$ & & 1.3 \\
\hline \multirow[t]{2}{*}{ Coenzyme } & Dehydroascorbate & C05422 & 1.0 & \\
\hline & Pantothenate & $\mathrm{C} 00864$ & & 0.7 \\
\hline \multirow[t]{4}{*}{ Nucleotide } & Adenosine & C00212 & & -1.3 \\
\hline & Adenine & $\mathrm{C} 00147$ & 0.5 & \\
\hline & N6-carbamoylthreonyladenosine & & 0.4 & 0.9 \\
\hline & Xanthosine & & & 0.8 \\
\hline Hormone & Gibberellate & C01699 & 3.3 & \\
\hline \multirow[t]{2}{*}{ Peptide } & Gamma-glutamylisoleucine & & & 0.7 \\
\hline & Gamma-glutamylvaline & & & 0.7 \\
\hline \multirow[t]{10}{*}{ Secondary metabolism } & Oleanolate & & -2.0 & \\
\hline & Benzyl alcohol & C00556 & 1.1 & -0.8 \\
\hline & Benzoyl-O-glucose & & 2.0 & -1.4 \\
\hline & Catechin & C06562 & & -1.6 \\
\hline & Naringenin-7-O-glucoside & & & -0.5 \\
\hline & Rutin & C05625 & & 0.4 \\
\hline & Catechin gallate & & & -2.3 \\
\hline & Gallate & C01424 & & -1.7 \\
\hline & Resveratrol & C01424 & & -1.9 \\
\hline & Loganin & C01433 & & -1.5 \\
\hline
\end{tabular}

Bold letters correspond to the highly significant different metabolites $F C(\mid \log 2$ (treatment/control)|) $\geq 1$.

shikimate, and putrescine concentrations and increased metabolites derived from aspartate family (methionine and $\mathrm{SAH})$ were observed in shade-derived samples. In the GAc treated samples, an increase of phenethylamine, aspartate, and alanine and a decrease of 2-aminobutyrate occurred. All metabolites from the carbohydrate pathway were reduced 

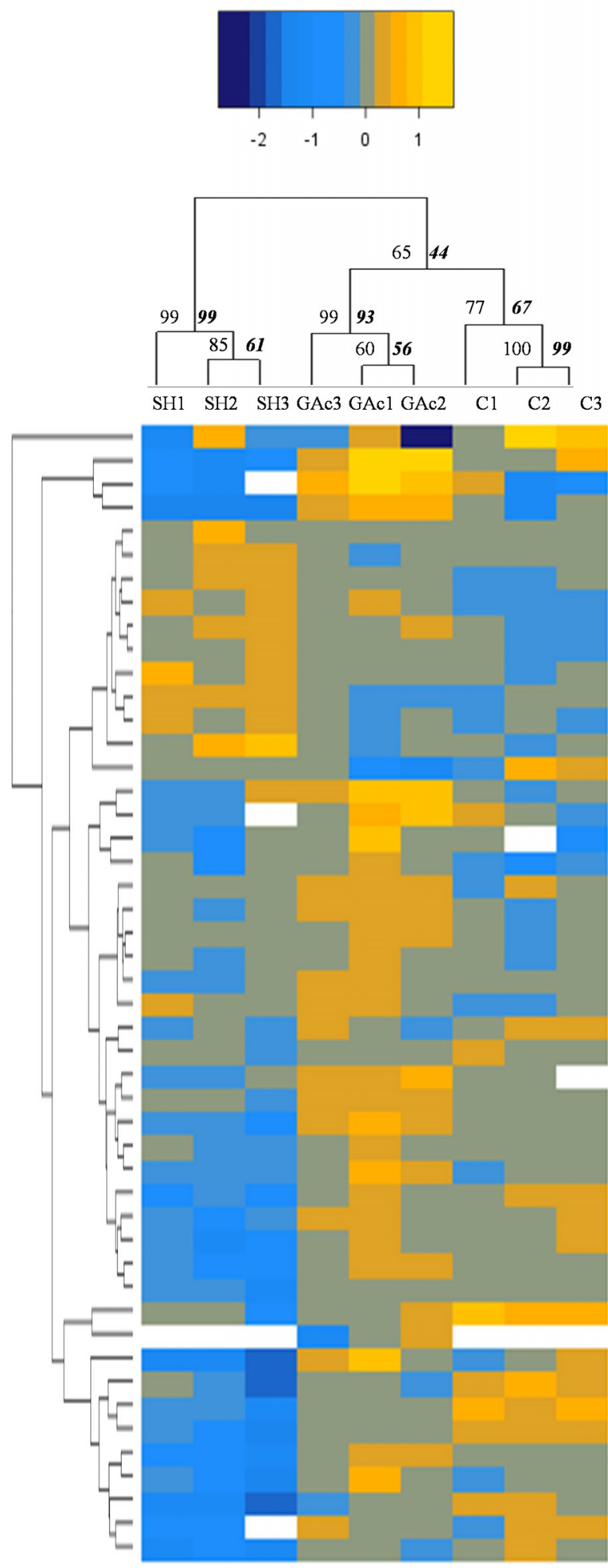

FIGURE 4 | Hierarchical cluster (A) and principal component analysis (B) of the significantly changed metabolites. Yellow and blue tones represent metabolites more and less abundant, respectively. The significance of dendrogram nodes was estimated by bootstrap analyses using 1000 permutations. Values represented in the left side of internal nodes are the
B

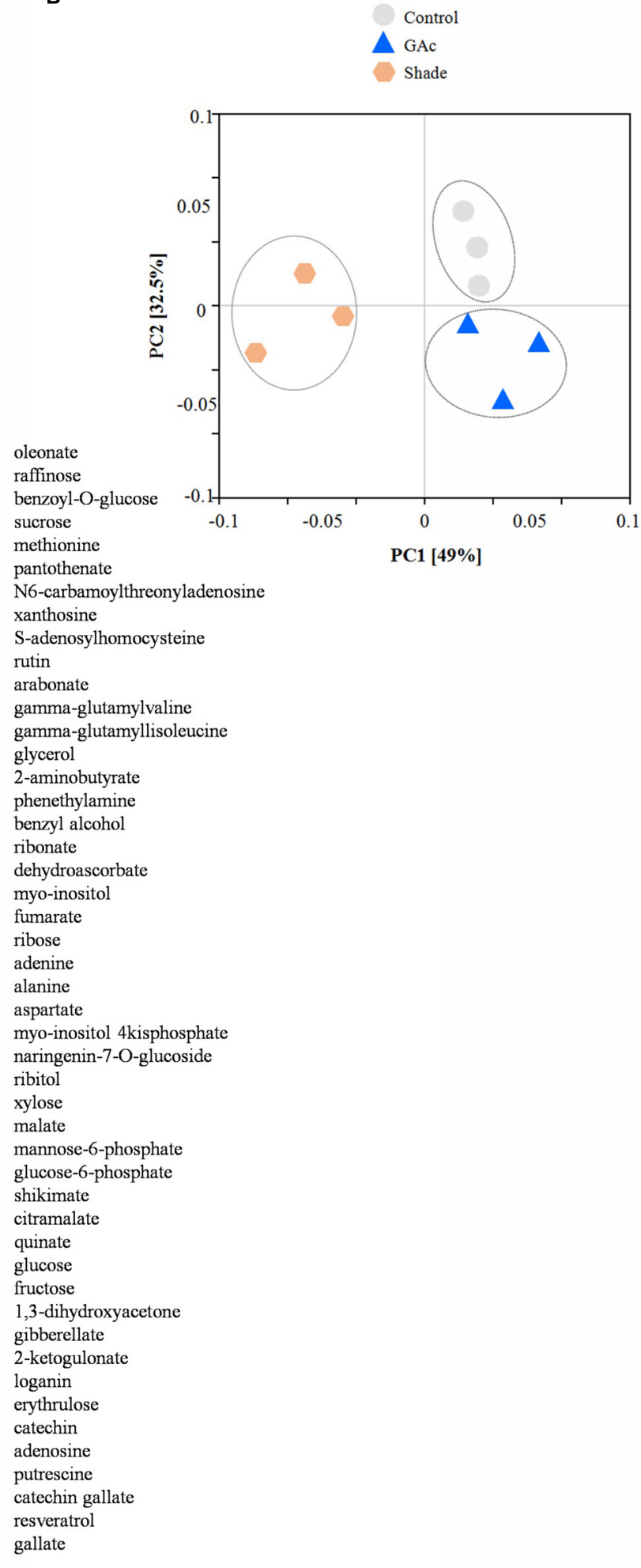

approximately unbiased $P$-values (AU), bold and italic values on the right side represented the bootstrap probability value. In PCA, the first and second components explain $81.5 \%$ of the total variation endorsed by the metabolite profile. Gray, blue and orange represent replicates from control, GAc and shade treatments, respectively. 


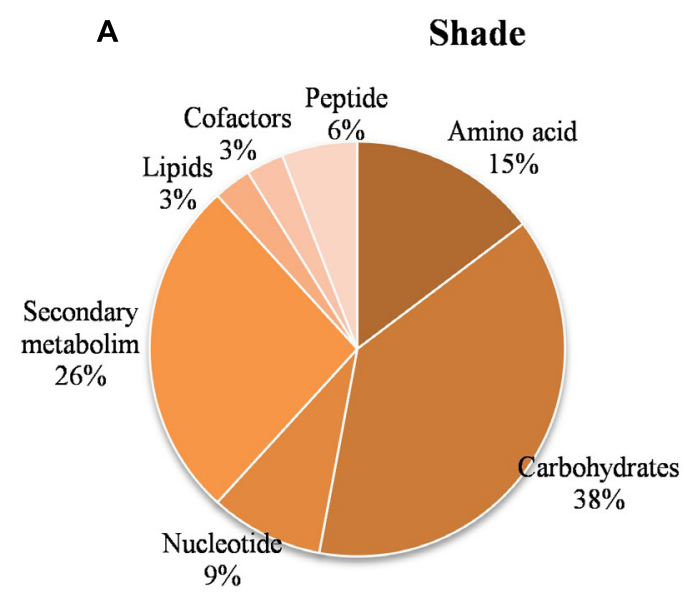

FIGURE 5 | Functional categorization of the $\mathbf{4 8}$ metabolites that showed significantly changes $(\boldsymbol{P}<\mathbf{0 . 0 5})$ in abundance. In shaded inflorescences (A), 34 metabolites from carbohydrate, secondary metabolism, amino acid, nucleotide, peptide, cofactor, and lipid functional pathways were significantly

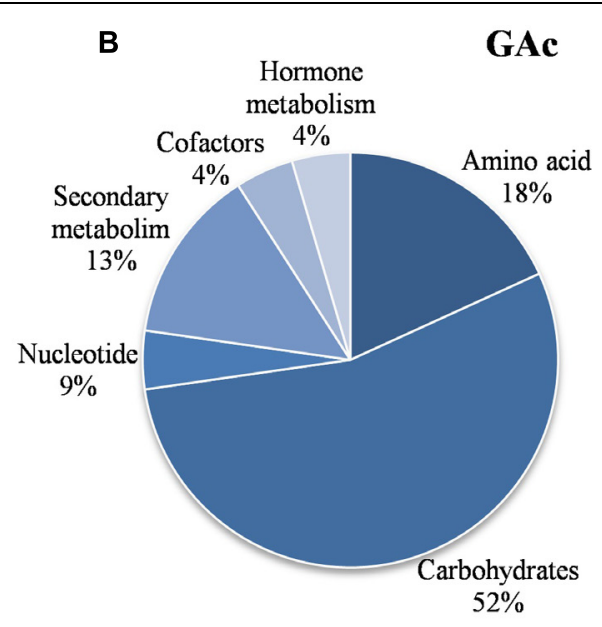

affected. In GAc-treated inflorescences (B), 19 metabolite contents from carbohydrate, amino acid, secondary metabolism, hormone, cofactor, and nucleotide pathways changed. Nine metabolites were changed in both the treatments. in shaded inflorescences except arabonate. Conversely, in GAc-treated samples, all metabolites increased except myoinositol tetrakisphosphate and erythrulose. Glycerol, a product from the lipids metabolism, highly increased in result of shade conditions. Gibberelate was detected only in the GAcderived samples, probably as the result of the exogenous application. Several metabolites from coenzyme and nucleotide metabolisms increased in both treatments except adenosine that was reduced in shade. Likewise, gamma-glutamylisoleucine (gamma-glu-lleu) and gamma-glutamylvaline (gamma-glu-val), from peptides metabolism, increased in the shade treatment. The concentration of metabolites derived from secondary metabolism was reduced in both treatments except two aromatic benzenoids (benzyl alcohol and benzyl-O-glucose) that increased in the GAc treatment and rutin that was increased in the shaded samples. Focusing on the metabolites with more pronounced changes [FC (| log 2 (treatment/control)| ) $\geq 1$ ], it was observed that raffinose, inositol, glycolysis, TCA cycle, shikimate, PAL and PA pathways were involved in the changes that occurred in inflorescences treated to enhance abscission rates (Figure 6). Sucrose and raffinose amounts changed in opposite directions in shade and GAc treated inflorescences, and a down- and up-regulation of the raffinose family oligosaccharides (RFOs) pathway was found in shade and GAc, respectively. Inositol and metabolites from the shikimate pathway (quinate and shikimate) were reduced in shade. Erythrulose and 1,3-dihydroxyacetone derived from glucose and glyceraldeyde-3-P in the glycolysis pathway were also reduced in this treatment. Concerning compounds associated with the TCA cycle, 2-ketogulonate, derived from oxaloacetate, was reduced in shaded samples and 2-aminobutyrate, derived from $\alpha$-ketoglutarate (via glutamate), was reduced in response to GAc spraying. PA metabolism, likewise derived from glutamate, was reduced in result of the shade treatment. Compounds from benzenoids family increased in GAc treated inflorescences whereas oleanolate was decreased. Flavonoids (catechin and catechin gallate), phenylpropanoids (resveratrol and gallate), benzyl-O-glucose and loganin were reduced in response to shade.

\section{Impacts on Bunch and Berry Quality}

Shade and GAc treatments reduced yield per plant, bunch weight and number of regular sized berries, in both cycles, when compared to untreated vines (Table 2). In the late production cycle, no differences in shot berries number were observed while in the early cycle, GAc promoted a higher number of these berries (407.1 shot berries), which was reflected in the increased number of total berries (512.6 berries per bunch) measured. Rachis length was shorter in bunches from vines submitted to shade and GAc, in the early production cycle. Nevertheless, bunch compactness was lower in plants that were shaded during flowering in both production cycles (5.1 and 10.5 berries $\mathrm{cm}^{-1}$ ) and higher in GAc treated plants in the early production cycle $\left(22.1\right.$ berries $\left.\mathrm{cm}^{-1}\right)$ when compared with control. Rachis weight was lower in both production cycles in bunches from shaded vines, and was higher in GAc treated bunches in late cycle. Regarding berry quality parameters, the weight and transversal diameter of the berries were reduced in grapes from GAc treated and shaded vines in late cycle, when compared with controls. In the early cycle, no significant differences were observed in berry diameter but shade lead to increased berry weight. Berry TSS content was higher in shaded vines comparing to the control in the late cycle, while differences in titratable acidity were not observed (Table 2). Both production cycle and the interaction production cycles $\times$ treatment significantly affected yield per plant, number of berries, number of shot berries, bunch compactness and berry diameter and berry weight $(P<0.05)$. Production cycle also affected average bunch weight and titrable acidity $(P<0.001)$. 


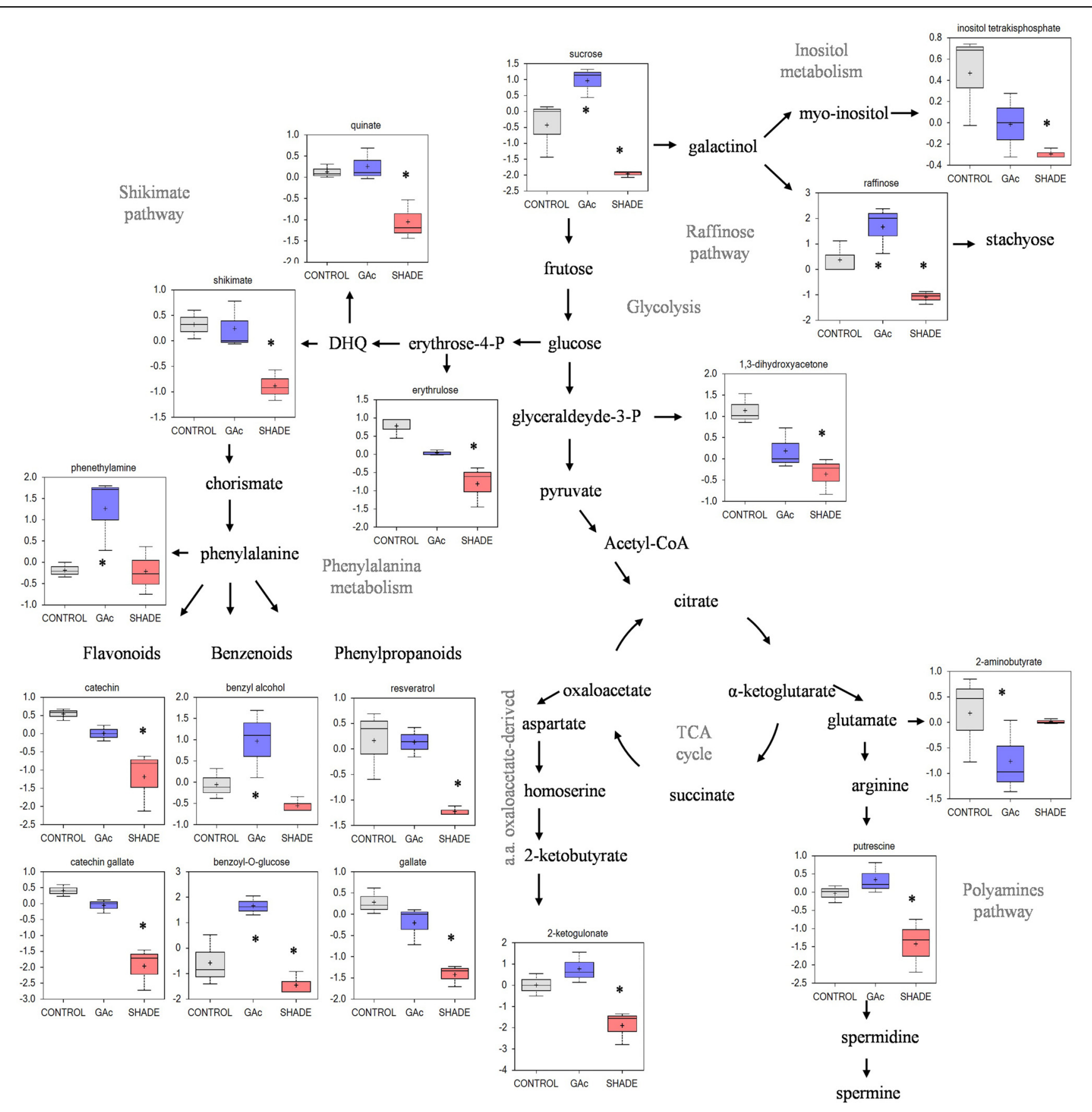

FIGURE 6 | Changes in metabolic profile in table grape inflorescences treated with GAC and Shade. Metabolites with highly significant differences are represented in the box plots and asterisks identify which treatment is different from the control $[P<0.05, \mathrm{FC}(\mid \log 2$ (treatment/control) $\mid) \geq 1]$. Data were $\log _{2}$ transformed after scale imputation median $=1$. Gray, blue, and orange represent samples from control, GAc and shade treatments, respectively.

\section{Discussion}

\section{Flower Abscission Induced by Hormonal and C-Starvation Stimuli}

The direct comparison of the changes in $V$. vinifera $\mathrm{L}$. inflorescences metabolite abundance that resulted from the imposition of two different abscission-triggering treatments was possible due to controlled conditions allowed from the experimental model used. Using potted plants growing under soilless greenhouse conditions, it was possible to apply both treatments to homogenous biological material. Moreover, this system allowed achieving improved plant growth and grape productivity, extending the harvest schedule and, relevant to the objectives of this work, obtaining more than one 
production cycle in the same agronomic year (Di Lorenzo et al., 2009).

The significant effect of climatic conditions on fruit set, revealed by the differences observed in natural flower drop rates between the two production cycles, can be explained by the influence exerted by the maximum temperatures registered during bloom in the late cycle that exceeded $35^{\circ} \mathrm{C}$ in the majority of the days during the bloom period (Supplementary Figure S1). Under these range of temperatures, fruit set is known to decrease due to reduction of ovule fertility (Kliewer, 1977) and pollen germination rates (Vasconcelos et al., 2009).

The Black Magic table grape cultivar showed to be sensitive to shade imposed during bloom, resulting in increased flower drop percentages in both production cycles while the response to GAc application showed to be dependent of microclimate conditions. Under this treatment, fruit set was impaired in the late production cycle while an increase was observed in the early cycle, which agrees with previous results (Reynolds and Savigny, 2004; Reynolds et al., 2006) in 3-years trials. The significant reduction of fruit set induced by the 12-days period shading during bloom (Table 1) suggests that this approach can be exploited as an effective method for thinning in table grape production, relying on the pronounced decline of net photosynthetic rate, which promotes a decrease on carbon resources available to both vegetative and reproductive sinks and increases the competition between them (Corelli Grappadelli et al., 1990; Byers et al., 1991; Zibordi et al., 2009). The moment of shade imposition matched a stage during which the vine carbon reserves reached a minimum, which coincides with the onset of bloom in grapevines (Zapata et al., 2004). During this sensible period, interruptions or partial sugar supply declines are known to promote flower abortion (Lebon et al., 2008). In the present study, monitoring daily rate of berry drop during the shade imposition period enabled us to verify that the maximum rate of berries drop depends on the global environmental conditions, occurring 2-4 DAB in late cycle and between 4 and $12 \mathrm{DAB}$ in early cycle, indicating precocity in C-shortage in the former cycle. Shading did not affect leaf area nor shoot growth, confirming previous observations that indicate that reproductive growth is more sensitive to environmental stress or limitation of resources than vegetative growth (Chiarello and Gulmon, 1991). The increased estimated leaf chlorophyll content in result from intercepted light reduction when compared with GAc treated vines, agrees with Ferree et al. (2001), and suggests an adaptability of the grapevine to low light intensity by increasing the PAR trapping efficiency (Cartechini and Palliotti, 1995).

The evidence that disturbances in growth regulators internal concentrations have an important influence on fruit set has been exploited in table grape production. In fact, GAc exogenous bloom application is commonly used as a mean to achieve cluster loosening (Dokoozlian and Peacock, 2001). Nonetheless, environment was demonstrated to play a major role in modulating the responses to growth regulator treatments, in particular the temperature. Low temperatures lead to suboptimal response while, under high temperature conditions, the response may be excessive (Wertheim and Webster, 2005). Thus, we suggest that the observed differences on GAc effectiveness to induce flower abscission and increase shot berries number was related to the environmental conditions and physiological stage of the vines. During the late production cycle, vines are developing under more intense stress conditions, and had a smaller leaf area and shoot length than in the early cycle. Plants are expected to have lower carbohydrates and endogenous GA levels, resulting in a higher sensitivity to exogenously applied GAc and a reduction of fruit set comparing to control. Sensitivity to exogenously applied GAc was reported to be inversely related with endogenous gibberellins levels (Boll et al., 2009).

\section{Sugar Metabolism and Other Energy Sources}

Sucrose, glucose, and fructose are the major phloem sap sugars which feed the developing vine inflorescences (Lebon et al., 2008). The reduction on the sucrose content in inflorescences developing under control conditions observed $4 \mathrm{DAB}$, at the onset of natural drop, agrees with previous observations (Glad et al., 1992) reporting that this sugar, predominant in this stage, represents $85 \%$ in sap flow at full bloom and declines thereafter to $60 \%$ at the end of fertilization, explaining natural drop. Our results were expected in confirming that decreased light intensity inhibits photosynthesis and sugar accumulation in inflorescences but showed that, in contrast, GAc treatment did not affect photosynthesis and even increased the inflorescence sugar content. Noticeably, both treatments resulted in similar rates of flower abscission (Table 1 and Figure 3). Shade induced more pronounced effects than GAc spraying concerning the number of changed metabolites (Table 3). Essentially, all carbon metabolites identified showed to be present in lower amounts in shaded and in higher levels in GAc samples, including sucrose and glucose, as well as TCA intermediates (malate, citramalate, and fumarate), and intermediates of the RFO pathway, such as raffinose (Table 3 and Figure 6). The decline of carbohydrate transport metabolism that occurred in shade agrees with abscission modulation induced by NAA and by shade in apple (Zhu et al., 2011). It was also verified that under shade, as in other stress conditions, the synthesis of glycerol may be favored via starch degradation, as an energy resource, and decrease of the carbon flow into TCA cycle (Xia et al., 2014). Regarding amino acid pathways, in shaded samples, the concentration of quinate, shikimate, and putrescine decreased while methionine and SAH increased (Table 3 and Figure 6). In addition, adenosine, which plays an important role in biochemical processes as energy transfer [adenosine triphosphate and diphosphate (ATP and ADP) and in signal transduction cyclic adenosine monophosphate (cAMP)], also decreased. Shade conditions led to a signature of carbon/nitrogen $(\mathrm{C} / \mathrm{N})$ imbalance with lower energy and carbon metabolites, biosynthetic precursors such as shikimate and nitrogen-rich compounds associated with anabolic activity such as putrescine, and higher proteinogenic amino acid such as methionine that may result from protein turnover to free up amino acid carbon backbones for energy utilization. Likewise, the increased amount of pantheonate (vitamin $\mathrm{B}_{5}$ ) whose biosynthetic pathway involves valine and alanine amino acids (Raman and Rathinasabapathi, 2004) observed in shade-derived inflorescences support the hypothesis of proteinogenic amino acids abundance from protein turnover. On the other hand, since all Calvin cycle metabolites 
were present in lower amounts in shaded samples, the pathway of pantheonate functioning as CoA biosynthesis precursor needs a more detailed evaluation. Our results are in accordance with Baena-González and Sheen (2008) which review physiological and molecular responses associated with plant energy deficit, including activation of catabolic pathways to provide alternative nutrient, metabolite and energy sources, and a decline in the activity of biosynthetic enzymes to preserve energy, and with Aziz (2003) showing that shading the vines at full bloom causes a decrease in both sugars and free PAs and leads to a substantial increase of abscission.

Gibberellins are involved in pathways of regulation of flowering and fruit-set in grapes, as active GAs, mainly $G_{1}$, peaks at anthesis and decrease thereafter (Perez et al., 2000; Giacomelli et al., 2013). GAc is commonly applied during bloom to reduce fruit set but the molecular mechanisms underlying this process are largely unknown. In Arabidopsis thaliana, GAc induces increased 3-P-glycerate and promotes plant growth rate (Meyer et al., 2007; Ribeiro et al., 2012). In this study, GAc application led to generalized up-regulation of both primary (carbohydrates, amino acid, coenzyme, and nucleotide pathways) and secondary metabolisms (Table 3 and Figure 6). Since no changes in photosynthetic rate (source) were detectable in samples submitted to this treatment, we hypothesize that an increase on inflorescences sink strength occurs after GAc treatments, resulting in the formation of king berries, with higher potential to compete for carbohydrates and other metabolites and higher growth rate, inhibiting the development and inducing abscission of later flowers. Regarding TCA cyclederived metabolites, only 2 -aminobutyrate from glutamate family decreased as a result of GAc while, on the other hand, metabolites derived from aromatic amino acid phenylalanine and from aspartate family (alanine and aspartate) showed the opposite trend (Table 3 and Figure 6). Glutamate derives from $\alpha$-ketoglutarate and can be involved in the biosynthesis of 2aminobutyrate or, alternatively, in the biosynthesis of arginine and PAs biosynthesis. According to our results, it can be hypothesized that the pathway from glutamate to PAs is favored when vines are treated with GAc, in contrast with biosynthesis of 2-aminobutyrate.

\section{Cell Wall Modifications}

The recorded increase of CW monosaccharides in samples from both abscission-triggering treatments (Table 3) sounds with the known CW disassembly and remodeling processes that occur during pedicel AZ formation as part of the coordinated series of modifications that ultimately lead to CW loosening, cell separation and differentiation of a protective layer on the proximal side after organ detachment (Lee et al., 2008). The increased arabonate concentration, which is a metabolite derived from arabinose, as consequence of the shade treatment contrasts with the observations in GAc treated inflorescences where xylose was the increased monosaccharide (Table 3). These differences are likely to reflect differences on target CW polymers, with pectins and xyloglucans more affected by shade or GAc, respectively. Pectin changes depends on the type of substitutions and branches in their backbone and are considered a central event (Fukuda et al., 2013) since the continuity between AZ cells is preserved by the middle lamellae, which is rich in this class of polymers, responsible for cell-cell adhesion. Pectins are additionally responsible for modulating the CW porosity and, in so, controlling the enzymes access to their substrates (Baron-Epel et al., 1988). Augmented arabinose levels may also indicate a higher substitution of pectic polysaccharides with arabinosyl residues which can work as plasticizers (Harholt et al., 2010) and be involved in the formation of the protective layer in the proximal area. In fact, during abscission, CWs of the proximal area are relatively richer in cellulose, arabinose-rich polymers and pectin, and poorer in xylan-rich polysaccharides and lignin when compared with AZ CWs (Lee et al., 2008). Regarding the detection of increased concentrations of xylose in samples from GAc-treated inflorescences, it may similarly reflect $\mathrm{CW}$ loosening processes needed for organ shed or CW strengthening requirements, but through action on cellulose-xyloglucan contact points. Xyloglucans are closely intertwined with cellulose at limited sites designed as "biomechanical hotspots", promoting selective targets majorly modulating CW loosening (Park and Cosgrove, 2012). Our results confirm the putative role of xyloglucans in providing $\mathrm{CW}$ strength for attachment of organs and its dynamic metabolism in mediating abscission, in response to some triggering signals. These assumptions are further supported by gene expression assays since it has been demonstrated that the activation of the abscission molecular machinery involves alterations of genes encoding CW remodeling enzymes acting on structural polysaccharides leading to the middle lamellae breakdown, accompanied by distortion and dissolution of primary CWs along the abscission plane (Lashbrook and Cai, 2008; Lee et al., 2008; Agusti et al., 2009; Meir et al., 2010; Zhu et al., 2011; Peng et al., 2013; Wang et al., 2013) and glycosyl hydrolysis (Lashbrook and Cai, 2008; Singh et al., 2011, 2013). The pattern of differential temporal regulation of distinct classes of CW-related genes (Lashbrook and Cai, 2008) additionally suggests that the differences observed between treatments may be the result of triggering their action at different stages of the process. It should be noted that the samples here investigated include cells other than AZ. Hence, as CWs represent primarily communication between the plant and the environment, a role in adaptation to the imposed abiotic stress can be discussed. The observed difference in CW composition are known to be related to events such as localized cell division, arrestment of elongation and modifications in the differentiation status, to impact anatomy and development (Braidwood et al., 2013).

\section{Markers of Oxidative Stress}

Likewise, both abscission-triggering stimuli lead to oxidative stress related metabolism, but the results suggest that different pathways are tracked. Some of the significant increases observed are related to metabolites associated with oxygen stress remediation. Gamma-glutamyl amino acids, observed in shaded samples, are intermediates in the glutathione synthesis cycle (Table 3) and dehydroascorbate, observed in GAc treated samples, indicates responses to elevated oxidative 
stress conditions related to the ROS scavenging coupled ascorbate/dehydroascorbate cycle (Table 3). During abscission a continuous increase of ROS production is known to occur. ROS role in abscission encompasses multiple steps of signaling (Sakamoto et al., 2008) associated with ROS-sugar-hormone cross talk (Botton et al., 2011) and ROS-mediated oxidative damage/cleavage on CW components leading to cell separation (Cohen et al., 2014). Regulation of excessive ROS by the free radical scavenging systems comprises essential enzymatic components and non-enzymatic molecules such as ascorbate and glutathione. Glutathione and ascorbate play important roles individually or through the ascorbate glutathione cycle, having specific functions besides interchangeable antioxidants (Bohnert and Sheveleva, 1998). Our results suggest that distinct metabolitedependent responses are triggered by each treatment agreeing with the independence and interdependence of glutathione and ascorbate in peroxide metabolism model proposed by Foyer and Noctor (2011).

\section{Hormone Regulation}

The occurrence of an ABA peak $3 \mathrm{DAB}$ in control inflorescences (Figure 3E) preceding the rise of natural flower drop (4-12 DAB; Figure 2A) is in accordance with previous works describing hormones as mediators of the $\mathrm{AZ}$ cell responses to abscission signals (Estornell et al., 2013). Interplay between a decrease of sugar, increases levels of ABA, ethylene, and ROS in organ predicted to abscise were verified, taking place before the onset of abscission (Botton et al., 2011). Our results confirm ABA as a component of the self-regulatory mechanism that adjusts fruit load to carbon supply occurring under natural conditions or following treatments (Gomez-Cadenas et al., 2000).

The increase of inflorescence IAA (auxin) concentration registered in both treatments (Figure 3F) may suggest that IAA was accumulated on the proximal side of abscission and the auxin flux to the distal organ predict to abscise was interrupted. It has been showed that a constant auxin transport through the AZ is needed to prevent abscission (Taylor and Whitelaw, 2001) and a auxin depletion linked with acquisition of ethylene sensitivity within AZ cells is needed to its induction (Meir et al., 2010; Basu et al., 2013). Our results are also consistent with the auxin gradient theory (Addicott et al., 1955) based on the evidence that auxin application in the proximal end of AZ explants accelerates abscission whereas when applied at the distal end delays it, and suggesting that changes in auxin gradients may act in signaling the onset of senescence and abscission. Ethylene and auxins are critical factors that regulate the onset of abscission (Basu et al., 2013) in a mechanism where the auxin depletion inside AZs and an altered expression of auxin-regulated genes induce the acquisition of sensitivity to ethylene and $A Z$ activation. The increase of methionine and $\mathrm{SAH}$, which are intermediates in the ethylene biosyntheses, observed in shaded-treated samples (Table 3) can be associated with the increase of ethylene, acting as a trigger in the abscission process (Meir et al., 2010). SAM, derived from methionine, is also the precursor of the spermidine and spermine biosynthesis pathway or alternatively can be used on the synthesis of ACC which is the immediate precursor of ethylene (Wang et al., 2002).

\section{Secondary Metabolism}

In shade, decreased loganin content, which is a monoterpenoid intermediate in the production of indole alkaloids, and several phenylpropanoids, benzenoids, and flavonoids was observed (Table 3 and Figure 6), indicating suppression of biosynthesis of secondary metabolites and a slowdown of biochemical reactions in the AZ and neighboring tissues (Wang et al., 2013). This significant reduction can also mean an initial delay in fruit set and development under these conditions due to drastic reductions in carbon supply during this period, when compared to control samples. In this later situation, the accumulation of compounds characteristics of berry development, mainly in red and black varieties as 'Black Magic', is known to be already started (Braidot et al., 2008). The decreased catechin can be also the result of the condensation of such flavanols, as observed after ethylene exogenous application (Rizzuti et al., 2015). Among the metabolites analyzed, flavonoid rutin was the exception in the general trade, showing a slightly increase in shade, probably due to its potential as strong radical scavenger and inhibitor of lipid peroxidation (Kumar and Pandey, 2013). On the other hand, GAc application led to a general advance in berry development in this stage and can have the opposite effect in ripening, depending on the cultivar (Teszlák et al., 2005). Comparing to the control, the aromatic compounds (benzenoids) showed increased accumulation in GAc treated samples (Table 3). Also in GAc, the decreased terpenoid oleonate levels measured suggests a reduction of steroids synthesis, which are membrane components that appears to control membrane fluidity and permeability and, in some plants, have a specific function in signal transduction (Piironen et al., 2000).

\section{Final Development of Reproductive Structures}

The treatments imposed to produce biological samples enriched in abscission signals affected final yield and quality in both production cycles and some implications can be ascertain with relevance for table grape production (Table 2). The reduction of the number of berries in the late production cycle in shade and GAc treatments lead to reductions of bunch weight and yield per plant, indicating that the two approaches were efficient in inducing abscission. However, in the late cycle, both treatments affected berry weigh and diameter in a detrimental way, which can be the result of a decreased seed number and weight (Reynolds et al., 2006). In early cycle, shade resulted in a successful thinning method reducing total berries number and improving berry weight and diameter. The shade treatment affected bunch characteristics, reducing rachis length and weight and still reducing the number of berries per centimeter of rachis, in both cycles. The observed effect on the rachis can result from competition for photoassimilates favoring vegetative growth in detriment of the development of reproductive organs (Chiarello and Gulmon, 1991). In the early cycle, GAc treatment showed to be ineffective as thinning method due to the increased number of shot berries, total berries number and bunch compactness. The high number of shot berries observed as a negative effect of GAc application was also described by Dokoozlian and Peacock (2001). Recently, in a study performed by Abu-Zahra and Salameh (2012) aimed at evaluating the impact of GAc spray 
(50 ppm at the end of bloom, 18 and 40 days after end of bloom) on 'Black Magic' grape quality, an increase of berries number, berry size, TSS, titratable acidity, and decreased color intensity was observed. Although, according to Cartechini and Palliotti (1995), shade during flowering has no effect on final berries sugar content, under our conditions, the shade treatments increased TSS in the late production cycle, which can be a direct result of the reduction of berries weight and diameter.

\section{A Mechanistic View of Flower Abscission Control in Vitis vinifera L.}

The analysis performed in the late cycle, when both treatments were efficient in inducing abscission, showed that GAc responses comprised a relatively low numbers of significant changes, while the shade treatment conduced to more dramatic physiological and metabolomic alterations (Table 3). These results allowed us to propose a mechanistic model to explain differences and common links for flower abscission determination in response to two stimuli (Figure 7). Comparing the composition in metabolites of grapevine inflorescences treated with the different abscission inducers (shade and GAc) and the control, we can conclude that abscission mechanisms triggered by hormonal application and via C-starvation are not based in the same pathways. A new insight on the mode of action of GAc during bloom is here provided, showing that it is based on a generally stimulation of cell metabolism and gene expression revealed by ribose and its derived metabolites, sugar, amino acid and PA metabolisms in the whole inflorescence and a highly significant inhibition of a glutamate sub-pathway related with 2-aminobutirate (Table 3), which can be a key step in the GAc metabolism in inflorescences at bloom stage and may participate in a cross talk between IAA and gibberellate. In other biological processes (Yamaguchi, 2008), it has been described that bioactive gibberellins and auxins can positively regulate flower abscission triggered by GAc spraying. On other hand, shade induced abscission through energy deprivation mechanisms showed by the decline of photosynthesis, carbon metabolism and biosynthetic activity. The increased accumulation of ethylene precursors suggests that these events may participate together with ethylene production (Table 3). The common markers of abscission were increased IAA concentration in inflorescences, which can be a result of an auxin gradient change through the $\mathrm{AZ}$, and increases in oxidative stress marker metabolites agreeing with previous studies in other species (Estornell et al., 2013). Despite the grapevine economic value and scientific relevance as a model species, this study provides the first mechanistic view of the metabolomic changes responsible for the flower abscission regulation in this species (Figure 7), triggered by exogenous GAc application and reduction of the intercepted light, unraveling the complexity of its opposite effects and contributing to the advance in knowledge that will ultimately may lead to improved control of grapevine fruit set.

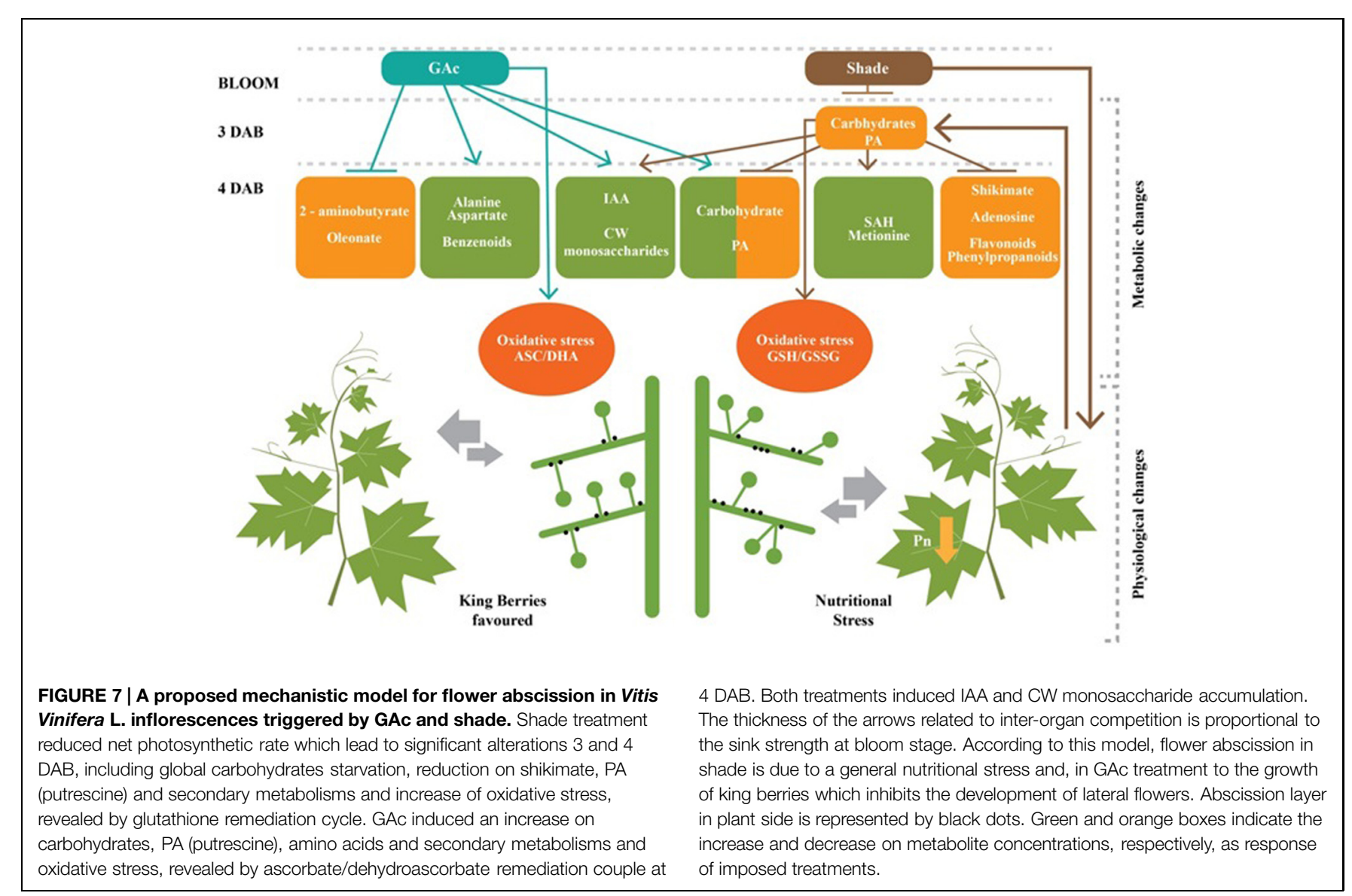




\section{Author Contributions}

SD, PS, CO, and LG were responsible for the conception and design of the experiments, SD and PS were responsible for acquisition of data, SD, VC, and AL performed the laboratory analyses, SD, PS, RD, CO, and LG interpreted the data. All authors drafted and approved the manuscript. RD, CO, and LG steered the whole project.

\section{Acknowledgments}

This work was supported by the Portuguese Fundação para a Ciência e a Tecnologia (FCT) through project

\section{References}

Abu-Zahra, T. R., and Salameh, N. M. (2012). Influence of gibberellic acid and cane girdling on berry size of black magic grape cultivar. Middle East J. Sci. Res. 11, 718-722.

Addicott, F. T., Lynch, R. S., and Carns, H. R. (1955). Auxin gradient theory of abscission regulation. Science 121, 644-645. doi: 10.1126/science.121.3148.644

Agusti, J., Merelo, P., Cercos, M., Tadeo, F., and Talon, M. (2009). Comparative transcriptional survey between laser-microdissected cells from laminar abscission zone and petiolar cortical tissue during ethylene-promoted abscission in citrus leaves. BMC Plant Biol. 9:127. doi: 10.1186/1471-22299-127

Aziz, A. (2003). Spermidine and related metabolic inhibitors modulate sugar and amino acid levels in Vitis vinifera L.: possible relationships with initial fruitlet abscission. J. Exp. Bot. 54, 355-363. doi: 10.1093/jxb/erg029

Baena-González, E., and Sheen, J. (2008). Convergent energy and stress signaling. Trends Plant Sci. 13, 474-482. doi: 10.1016/j.tplants.2008.06.006

Baron-Epel, O., Gharyal, P. K., and Schindler, M. (1988). Pectins as mediators of wall porosity in soybean cells. Planta 175, 389-395. doi: 10.1007/BF00396345

Basak, A. (2011). Efficiency of fruitlet thinning in apple 'Gala Must' by use of metamitron and artificial shading. J. Fruit Ornam. Plant Res. 19, 51-62.

Basu, M. M., González-Carranza, Z. H., Azam-Ali, S., Tang, S., Shahid, A. A., and Roberts, J. A. (2013). The manipulation of auxin in the abscission zone cells of Arabidopsis flowers reveals that indoleacetic acid signaling is a prerequisite for organ shedding. Plant Physiol. 162, 96-106. doi: 10.1104/pp.113.216234

Bohnert, H. J., and Sheveleva, E. (1998). Plant stress adaptations - making metabolism move. Curr. Opin. Plant Biol. 1, 267-274. doi: 10.1016/S13695266(98)80115-5

Boll, S., Lang, T., Hofmann, H., and Schwappac, P. (2009). Correspondence between gibberellin-sensitivity and pollen tube abundance in different seeded vine varieties. Mitt. Klosterneub. 59, 129-133.

Bonghi, C., Tonutti, P., and Ramina, A. (2000). Biochemical and molecular aspects of fruitlet abscission. Plant Growth Regul. 31, 35-42. doi: 10.1023/A:1006338210977

Botton, A., Eccher, G., Forcato, C., Ferrarini, A., Begheldo, M., Zermiani, M., et al. (2011). Signaling pathways mediating the induction of apple fruitlet abscission. Plant Physiol. 155, 185-208. doi: 10.1104/pp.110.165779

Braidot, E., Zancani, M., Petrussa, E., Peresson, C., Bertolini, A., Patui, S., et al. (2008). Transport and accumulation of flavonoids in grapevine (Vitis vinifera L.). Plant Signal. Behav. 3, 626-32. doi: 10.4161/psb.3.9.6686

Braidwood, L., Breuer, C., and Sugimoto, K. (2013). My body is a cage: mechanisms and modulation of plant cell growth. New Phytol. 201, 388-402. doi: $10.1111 / \mathrm{nph} .12473$

Byers, R., Barden, J., Polomski, R., Young, R., and Carbaugh, D. (1990). Apple thinning byphotosynthetic inhibition. J. Am. Soc. Hort. Sci. 115, 14-19.

Byers, R., Carbaugh, D. C. P., and Wolf, T. (1991). The influence of low light on apple fruit abscission. J. Hort. Sci. Biotechnol. 66, 7-18.

Byers, R., Lyons, J., and Yoder, K. (1985). Peach and apple thining by shading andphotosynthetic inhibition. J. Hort. Sci. 4, 465-472.
"VitiShade: PTDC/AGR-GPL/116923/2010" and the Ph.D. grant SFRH/BD/69076/2010 to SD, by the Sicilian Region through the Multiannual Research Project "Soilless Cultivation on Table Grape Production." We acknowledge Dr. Joana Fino for bioinformatics assistance and Dr. Danny Alexander and his team at Metabolon (Durham, NC, USA) for metabolomic analysis.

\section{Supplementary Material}

The Supplementary Material for this article can be found online at: http://journal.frontiersin.org/article/10.3389/fpls.2015.00457

Cartechini, A., and Palliotti, A. (1995). Effect of shading on vine morphology and productivity and leaf gas exchange characteristics in grapevines in the field. Am. J. Enol. Vitic. 46, 227-234.

Chiarello, N. R., and Gulmon, S. L. (1991). "Stress effects on plant reproduction," in Response of Plants to Multiple Stresses, eds H. A. Mooney, W. E. Winner, and A. J. Pell (New York, NY: Academic Press), 161-188. doi: 10.1016/B978-0-08092483-0.50013-X

Cohen, M. F., Gurung, S., Fukuto, J. M., and Yamasaki, H. (2014). Controlled free radical attack in the apoplast: a hypothesis for roles of $\mathrm{O}, \mathrm{N}$ and $\mathrm{S}$ species in regulatory and polysaccharide cleavage events during rapid abscission by Azolla. Plant Sci. 217-218, 120-126. doi: 10.1016/j.plantsci.2013.12.008

Corelli Grappadelli, L., Sansavini, S., and Ravaglia, G. F. (1990). "Effects of shade and sorbitol on fruit growth andabscission in apple," in Proceedings of the XXIII International Horticultural Congress, Florence, 620.

Dal Cin, V., Danesin, M., Boschetti, A., Dorigoni, A., and Ramina, A. (2005). Ethylene biosynthesis and perception in apple fruitlet abscission (Malus domestica L. Borck). J. Exp. Bot. 56, 2995-3005. doi: 10.1093/jxb/eri296

Dal Cin, V., Velasco, R., and Ramina, A. (2009). Dominance induction of fruitlet shedding in Malus $\mathrm{x}$ domestica (L. Borkh): molecular changes associated with polar auxin transport. BMC Plant Biol. 9:139. doi: 10.1186/1471-22299-139

Damesin, C., and Lelarge, C. (2003). Carbon isotope composition of currentyear shoots from Fagus sylvatica in relation to growth, respiration and use of reserves. Plant Cell Environ. 26, 207-219. doi: 10.1046/j.13653040.2003.00951.x

Davière, J.-M., and Achard, P. (2013). Gibberellin signaling in plants. Development 140, 1147-1151. doi: 10.1242/dev.087650

Davies, C., Wolf, T., Robinson, S. P. (1999). Three putative sucrose transporters are differentially expressed in grapevine tissues. Plant Sci. 147, 93-100. doi 10.1016/S0168-9452(99)00059-X

Di Lorenzo, R., Gambino, C., and Dimauro, B. (2009). "La coltivazione dell'uva da tavola in fuori suolo: stato attuale e prospettive," in Proceedings of the XXXIst World Congress Vine Wine 15-20 June, 2008 (Verona: OIV), 82, 33-44.

Di Lorenzo, R., Scafidi, P., and Gambino, C. (2014). "Soiless table grape production," in Proceedings of the Seventh International Table Grape Symposium 11-14 November 2014, Mildura, VIC, 24-25.

Dokoozlian, N. K. (ed.). (1998). "Use of plant growth regulators in table grape production in California," in Proceedings of the University of California Table Grape Production Course, Visalia, 200-210.

Dokoozlian, N. K., and Peacock, W. L. (2001). Gibberellic acid applied at bloom reduces fruit set and improves size of 'crimson seedless' table grapes. HortScience 36, 706-709.

Else, M. A., Stankiewicz-Davies, A. P., Crisp, C. M., and Atkinson, C. J. (2004). The role of polar auxin transport through pedicels of Prunus avium L. in relation to fruit development and retention. J. Exp. Bot. 55, 2099-2109. doi: $10.1093 / \mathrm{jxb} / \mathrm{erh} 208$

Estornell, L. H., Agustí, J., Merelo, P., Talón, M., and Tadeo, F. R. (2013). Elucidating mechanisms underlying organ abscission. Plant Sci. 199-200, 4860. doi: $10.1016 /$ j.plantsci.2012.10.008 
Evans, A., DeHaven, C., and Barrett, T. (2009). Integrated, nontargeted ultrahigh performance liquid chromatography/electrospray ionization tandem mass spectrometry platform for the identification and relative. Anal. Chem. 16, 6656-6667. doi: 10.1021/ac901536h

Ferree, D. C., McArtney, S. J., and Scurlock, D. M. (2001). Influence of irradiance and period of exposure on fruit set of french-american hybrid grapes. J. Am. Soc. Hortic. Sci. 126, 283-290.

Foyer, C. H., and Noctor, G. (2011). Ascorbate and glutathione: the heart of the redox hub. Plant Physiol. 155, 2-18. doi: 10.1104/pp.110.167569

Fukuda, K., Yamada, Y., Miyamoto, K., Ueda, J., and Uheda, E. (2013). Separation of abscission zone cells in detached Azolla roots depends on apoplastic $\mathrm{pH}$. J. Plant Physiol. 170, 18-24. doi: 10.1016/j.jplph.2012.08.008

Giacomelli, L., Rota-Stabelli, O., Masuero, D., Acheampong, A. K., Moretto, M., Caputi, L., et al. (2013). Gibberellin metabolism in Vitis vinifera L. during bloom and fruit-set: functional characterization and evolution of grapevine gibberellin oxidases. J. Exp. Bot. 64, 4403-4419. doi: 10.1093/jxb/ert251

Giulia, E., Alessandro, B., Mariano, D., Andrea, B., Benedetto, R., and Angelo, R. (2013). Early induction of apple fruitlet abscission is characterized by an increase of both isoprene emission and abscisic acid content. Plant Physiol. 161, 1952-1969. doi: 10.1104/pp.112.208470

Glad, C., Regnard, J.-L., Querou, Y., Brun, O., and Morot-Gaudry, J.-F. (1992). Phloem sap exudates as a criterion for sink strength appreciation in Vitis vinifera cv. Pinot noir grapevines. Vitis 31, 131-138.

Gomez-Cadenas, A., Mehouachi, J., Tadeo, F. R., Primo-Millo, E., and Talon, M. (2000). Hormonal regulation of fruitlet abscission induced by carbohydrate shortage in citrus. Planta 210, 636-643. doi: 10.1007/s0042500 50054

Harholt, J., Suttangkakul, A., and Scheller, H. V. (2010). Biosynthesis of pectin. Plant Physiol. 153, 384-395. doi: 10.1104/pp.110.156588

Hed, B., Ngug, H. K., and Travis, J. W. (2011). Use of gibberellic acid for management of bunch rot on chardonnay and vignoles grape. Plant Dis. 95, 269-278. doi: 10.1094/PDIS-05-10-0382

Hopping, M. E. (1976). Effect of bloom applications of gibberellic acid on yield and bunch rot of the wine grape 'Seibel 5455'. N. Z. J. Exp. Agric. 4, 103-107. doi: 10.1080/03015521.1976.10425853

Kelen, M., Demiralay, E. Ç., Şen, S., and Alsancak, G. Ö. (2004). Separation of abscisic acid, Indole-3-Acetic acid, gibberellic acid in $99 \mathrm{R}$ (Vitis berlandieri $\mathrm{x}$ Vitis rupestris) and Rose Oil (Rosa damascena Mill.) by reversed phase liquid chromatography. Turkish J. Chem. 28, 603-610.

Kliewer, W. M. (1977). Effect of high temperatures during the bloom-set period on fruit-set, ovule fertility, and berry growth of several grape cultivars. Am. J. Enol. Vitic. 28, 215-222.

Kumar, S., and Pandey, A. K. (2013). Chemistry and biological activities of flavonoids: an overview. ScientificWorldJournal 2013:162750. doi: $10.1155 / 2013 / 162750$

Lashbrook, C. C., and Cai, S. (2008). Cell wall remodeling in Arabidopsis stamen abscission zones: temporal aspects of control inferred from transcriptional profiling. Plant Signal. Behav. 3, 733-736. doi: 10.4161/psb.3. 9.6489

Lebon, G., Duchêne, E., Brun, O., Magné, C., and Clément, C. (2004). Flower abscission and inflorescence carbohydrates in sensitiveand non-sensitive cultivars of grapevine. Sex Plant Reprod. 17, 71-79. doi: 10.1007/s00497-004$0217-9$

Lebon, G., Wojnarowiez, G., Holzapfel, B., Fontaine, F., Vaillant-Gaveau, N., and Clément, C. (2008). Sugars and flowering in the grapevine (Vitis vinifera L.). J. Exp. Bot. 59, 2565-2578. doi: 10.1093/jxb/ern 135

Lee, Y., Derbyshire, P., Knox, J. P., and Hvoslef-Eide, A. K. (2008). Sequential cell wall transformations in response to the induction of a pedicel abscission event in Euphorbia pulcherrima (poinsettia). Plant J. 5, 993-1003. doi: 10.1111/j.1365313X.2008.03456.x

Li, C., Wang, Y., Huang, X., Li, J., Wang, H., and Li, J. (2013). De novo assembly and characterization of fruit transcriptome in Litchi chinensis Sonn and analysis of differentially regulated genes in fruit in response to shading. BMC Genomics 14:552. doi: 10.1186/1471-2164-14-552

Li, J., and Yuan, R. (2008). NAA and ethylene regulate expression of genes related to ethylene biosynthesis, perception, and cell wall degradation during fruit abscission and ripening in 'Delicious' apples. J. Plant Growth Regul. 27, 283-295. doi: $10.1007 / \mathrm{s} 00344-008-9055-6$
Looney, N. E., and Wood, D. F. (1977). Some cluster thinning and gibberellic acid effects on fruit set, berry size, vine growth and yiels of De Chaunac grapes. Can. J. Plant Sci. 57, 653-659. doi: 10.4141/cjps77-096

Lorenz, D., Eichhorn, K., Bleiholder, H., Klose, R., Meier, U., and Weber, E. (1994). Phänologische entwicklungsstadien der Rebe (Vitis vinifera L. ssp. vinifera) - codierung und beschreibung nach der erweiterten BBCH-Skala. Vitic. Enol. Sci. 49, 66-70. doi: 10.1111/j.1755-0238.1995.tb00085.x

Meir, S., Philosoph-Hadas, S., Sundaresan, S., Selvaraj, K. S. V., Burd, S., Ophir, R., et al. (2010). Microarray analysis of the abscission-related transcriptome in the tomato flower abscission zone in response to auxin depletion. Plant Physiol. 154, 1929-1956. doi: 10.1104/pp.110.160697

Meyer, R. C., Steinfath, M., Lisec, J., Becher, M., Witucka-Wall, H., Törjék, O., et al. (2007). The metabolic signature related to high plant growth rate in Arabidopsis thaliana. Proc. Natl. Acad. Sci. U.S.A. 104, 4759-4764. doi: 10.1073/pnas.0609709104

Ohta, T., Masutomi, N., Tsutsui, N., Sakairi, T., Mitchell, M., Milburn, M. V., et al. (2009). Untargeted metabolomic profiling as an evaluative tool of fenofibrateinduced toxicology in Fischer 344 male rats. Toxicol. Pathol. 37, 521-535. doi: $10.1177 / 0192623309336152$

Park, Y. B., and Cosgrove, D. J. (2012). A revised architecture of primary cell walls based on biomechanical changes induced by substrate-specific endoglucanases. Plant Physiol. 158, 1933-1943. doi: 10.1104/pp.111.192880

Peng, G., Wu, J., Lu, W., and Li, J. (2013). A polygalacturonase gene clustered into clade E involved in lychee fruitlet abscission. Sci. Hortic. 150, 244-250. doi: 10.1016/j.scienta.2012.10.029

Perez, F. J., Viani, C., and Retamales, J. (2000). Bioactive gibberellins in seeded and seedless grapes: identification and changes in content during berry development. Am. J. Enol. Vitic. 51, 315-318.

Piironen, V., Lindsay, D. G., Miettinen, T. A., Toivo, J., and Lampi, A.-M. (2000). Plant sterols: biosynthesis, biological function and their importance to human nutrition. J. Sci. Food Agric. 80, 939-966. doi: 10.1002/(SICI)10970010(20000515)80:7<939::AID-JSFA644>3.0.CO;2-C

Raman, S. B., and Rathinasabapathi, B. (2004). Pantothenate synthesis in plants. Plant Sci. 167, 961-968. doi: 10.1016/j.plantsci.2004.06.019

Reynolds, A. G., Roller, J. N., Forgione, A., and De Savigny, C. (2006). Gibberellic acid and basal leaf removal: implications for fruit maturity, vestigial seed development, and sensory attributes of sovereign coronation table grapes. Am. J. Enol. Vitic. 57, 41-53.

Reynolds, A. G., and Savigny, C. (2004). Influence of girdling and gibberellic acid on yield components, fruit composition and vestigial seed formation of 'Sovereign Coronation' table grapes. HortScience 39, 541-544.

Ribeiro, D. M., Araújo, W. L., Fernie, A. R., Schippers, J. H. M., and Mueller-Roeber, B. (2012). Translatome and metabolome effects triggered by gibberellins during rosette growth in Arabidopsis. J. Exp. Bot. 63, 2769-2786. doi: 10.1093/jxb/err463

Rizzuti, A., Aguilera-Sáez, L. M., Gallo, V., Cafagna, I., Mastrorilli, P., Latronico, M., et al. (2015). On the use of ethephon as abscising agent in $\mathrm{cv}$. crimson seedless table grape production: combination of fruit detachment force, fruit drop, and metabolomics. Food Chem. 171, 341-350. doi: 10.1016/j.foodchem.2014.08.132

Roubelakis, K. A., and Kliewer, W. M. (1976). Influence of light intensity and growth regulators on fruit-set and ovule fertilization in grape cultivars under low temperature conditions. Am. J. Enol. Vitic. 27, 163-167.

Sakamoto, M., Munemura, I., Tomita, R., and Kobayashi, K. (2008). Reactive oxygen species in leaf abscission signaling. Plant Signal. Behav. 3, 1014-1015. doi: $10.4161 / \mathrm{psb} .6737$

Schneider, G. (1975). C-sucrose translocation in apple. J. Am. Soc. Hort. Sci. 103, 455-458.

Singh, A. P., Dubey, S., Lakhwani, D., Pandey, S. P., Khan, K., Dwivedi, U. N., et al. (2013). Differential expression of several xyloglucan endotransglucosylase/ hydrolase genes regulates flower opening and petal abscission in roses. $A o B$ Plants 5:plt030. doi: 10.1093/aobpla/plt030

Singh, A. P., Tripathi, S. K., Nath, P., and Sane, A. P. (2011). Petal abscission in rose is associated with the differential expression of two ethylene-responsive xyloglucan endotransglucosylase/hydrolase genes, RbXTH1 and RbXTH2. J. Exp. Bot. 62, 5091-5103. doi: 10.1093/jxb/err209

Smith, M. A., and Davies, P. J. (1987). "Monitoring polyamines in plant tissues by high performance liquid chromatography," in High Performance Liquid 
Chromatography Plant Science Modern Methods Plant Analysis New Server, Vol. 5, eds H. F. Linskens and J. F. Jackson (New York, NY: Springer-Verlag), 209-227.

Storey, J., and Tibshirani, R. (2003). Statistical significance for genomewide studies. Proc. Natl. Acad. Sci. U.S.A. 100, 9440-9445. doi: 10.1073/pnas.1530509100

Suzuki, R., and Shimodaira, H. (2006). Pvclust: an R package for assessing the uncertainty in hierarchical clustering. Bioinformatics 22, 1540-1542. doi: 10.1093/bioinformatics/btl117

Taylor, J. E., and Whitelaw, C. A. (2001). Signals in abscission. New Phytol. 151, 323-340. doi: 10.1046/j.0028-646x.2001.00194.x

Teszlák, P., Gaál, K., and Pour Nikfardjam, M. S. (2005). Influence of grapevine flower treatment with gibberellic acid $\left(\mathrm{GA}_{3}\right)$ on polyphenol content of Vitis vinifera L. wine. Anal. Chim. Acta 543, 275-281. doi: 10.1016/j.aca.2005.04.013

Vasconcelos, M. C., Greven, M., Winefield, C. S., Trought, M. C. T., and Raw, V. (2009). The flowering process of Vitis vinifera: a review. Am. J. Enol. Vitic 60, 411-434.

Wang, K. L.-C., Li, H., and Ecker, J. R. (2002). Ethylene biosynthesis and signaling networks. Plant Cell 14, 131-151. doi: 10.1105/tpc.001768

Wang, X., Liu, D., Li, A., Sun, X., Zhang, R., Wu, L., et al. (2013). Transcriptome analysis of tomato flower pedicel tissues reveals abscission zone-specific modulation of key meristem activity genes. PLOS ONE 8:e55238. doi: 10.1371/journal.pone. 0055238

Weaver, R. J., McCune, S. B., and Hale, C. R. (1962). Effect of plant regulators on set and berry development in certain seedless varieties of Vitis vinifera L. Vitis 3, 84-96.

Wertheim, S. J., and Webster, A. B. (2005). "Manipulation of growth and development by plant bioregulators," in Fundamentals of Temperate Zone Tree Fruit Production, eds J. Tromp, A. D. Webster, and S. J. Wertheim (Ithaca: Universidade de Cornell; Backhuys), 267-294.

Whitelaw, C. A., Lyssenko, N. N., Chen, L., Zhou, D., Mattoo, A. K., and Tucker, M. L. (2002). Delayed abscission and shorter internodes correlate with a reduction in the ethylene receptor leETR1 transcript in transgenic tomato. Plant Physiol. 128, 978-987. doi: 10.1104/pp.010782

Widmer, A., Kockerols, K., Schwan, S., Stadler, W., and Bertschinger, L. (2008). "Towards grower-friendly apple crop thinning by tree shading," in Proceedings of the International Conference Cultivation Technique Phytopatholigical Problems Organic Fruit-Growing, Weinsberg, 314-318.

Xia, B.-B., Wang, S.-H., Duan, J.-B., and Bai, L.-H. (2014). The relationship of glycerol and glycolysis metabolism patway under hyperosmotic stress in Dunaliella salina. Cent. Eur. J. Biol. 9, 901-908. doi: 10.2478/s11535-0140323-0

Yamaguchi, S. (2008). Gibberellin metabolism and its regulation. Annu. Rev. Plant Biol. 59, 225-251. doi: 10.1007/s003440010039

Zapata, C., Deléens, E., Chaillou, S., and Magné, C. (2004). Partitioning and mobilization of starch and $\mathrm{N}$ reserves in grapevine (Vitis vinifera L.). J. Plant Physiol. 161, 1031-1040. doi: 10.1016/j.jplph.2003.11.009

Zhou, C., Lasko, A. N., Robinson, T. L., and Gan, S. (2008). Isolation and characterization of genes associated with shade-induced apple abscission. Mol. Genet. Genomics 280, 83-92. doi: 10.1007/s00438-008-0348-z

Zhu, H., Dardick, C., Beers, E., Callanhan, A., Xia, R., and Yuan, R. (2011). Transcriptomics of shading-induced and NAA-induced abscission in apple (Malus domestica) reveals a shared pathway involving reduced photosynthesis, alterations in carbohydrate transport and signaling and hormone crosstalk. BMC Plant Biol. 11:138. doi: 10.1186/1471-2229-11-138

Zibordi, M., Domingos, S., and Corelli Grappadelli, L. (2009). Thinning apples via shading: an appraisal under field conditions. J. Hort. Sci. Biotechnol. 84, 138-144.

Conflict of Interest Statement: The authors declare that the research was conducted in the absence of any commercial or financial relationships that could be construed as a potential conflict of interest.

Copyright () 2015 Domingos, Scafidi, Cardoso, Leitao, Di Lorenzo, Oliveira and Goulao. This is an open-access article distributed under the terms of the Creative Commons Attribution License (CC BY). The use, distribution or reproduction in other forums is permitted, provided the original author(s) or licensor are credited and that the original publication in this journal is cited, in accordance with accepted academic practice. No use, distribution or reproduction is permitted which does not comply with these terms. 